\title{
Global, Regional and National Geodetic Reference Frames for Geodesy and Geodynamics
}

\author{
JAROSLAW BOSY ${ }^{1}$
}

\begin{abstract}
In July 2003 the International Association of Geodesy (IAG) established the Global Geodetic Observing System (GGOS). The GGOS is integrating the three basic components: geometry, the earth rotation and gravity. The backbone of this integration is the existing global ground network, based on the geodetic space techniques: very long baseline interferometry, satellite laser ranging, global navigation satellite systems and Doppler orbitography and radiopositioning integrated by satellite. These techniques have to operate as one global entity and in one global reference frame. The global reference frame in the GGOS is a realization of the International Terrestrial Reference System (ITRS). The ITRS is a world spatial reference system co-rotating with the Earth in its diurnal motion in the space. The IAG Subcommision for the European Reference Frame (EUREF) in 1991 recommended that the terrestrial reference system for Europe should be coincident with ITRS at the epoch $t_{0}=1989.0$ and fixed to the stable part of the Eurasian Plate. It was named the European Terrestrial Reference System 89 (ETRS89). On the 2nd of June 2008, the Head Office of Geodesy and Cartography in Poland commenced operating the ASG-EUPOS multifunctional precise satellite positioning system. The ASG-EUPOS network defines the European Terrestrial Reference System ETRS89 in Poland. A close connection between the ASG-EUPOS stations and 15 out of 18 Polish EUREF permanent network stations controls the realization of the ETRS89 on Polish territory. This paper is a review of the global ITRS, as well as a regional and a national geodetic reference systems ETRS89.
\end{abstract}

Key words: Geodetic reference frame, ITRS, ETRS89, GGOS.

\section{Introduction}

Historically, geodesy was limited to determining the shape of the Earth; its gravity field and its rotation, including changes of these parameters over time. One of the main tasks of modern geodesy is to define and maintain this global terrestrial reference

1 Institute of Geodesy and Geoinformatics, Wroclaw University of Environmental and Life Sciences, Grunwaldzka 53, 50-357 Wrocław, Poland. E-mail: jaroslaw.bosy@up.wroc.pl frame. The quality of the reference frame realization has important implications for our ability to study both regional and global properties of the Earth, including post-glacial rebound, sea level change, plate tectonics, regional subsidence and loading, plate boundary deformation, and Earth orientation excitation (Altamimi et al., 2001; Seeber, 2003). However, with modern instrumentation and analytical techniques, the scope of the geodesy has been extended to include observed changes, i.e., the dynamics of mass transport within the Earth system (PlaG and Pearlman, 2009; Plag et al., 2009).

In response to those challenges, in July 2003 the International Association of Geodesy (IAG) established the Global Geodetic Observing System (GGOS: http://www.ggos.org). The GGOS represents IAG in the Group on Earth Observation (GEO) and GGOS is IAG's contribution to the Global Earth Observation System of Systems (GEOSS) (Plag and Pearlman, 2009; Plag et al., 2009).

The infrastructure of the GGOS consists of five distinct levels (Fig. 1), which depend on the distance to the Earth' surface (Rothacher et al., 2009).

According to the Fig. 1, Level 1 at the Earth surface, the GGOS consists of the ground networks of in situ instruments and space-geodetic tracking stations as well as the data and analysis centers. There are the Low Earth Orbit (LEO) satellites in Level 2, with highly accurate orbits determined utilizing the ground-based level as well as Level 3, that is the GNSS. The ground networks and the GNSS are crucial in positioning. Level 4 of the GGOS is comprised of the Moon and planets, that is particularly important for the dynamical reference frame. Finally, on Level 5 there are stable quasars, which provide the inertial reference frame fixed in space (PLAG and Pearlman, 2009; Plag et al., 2009).

Observations provided by geodetic satellite techniques on different levels (Fig. 1) are connected with 


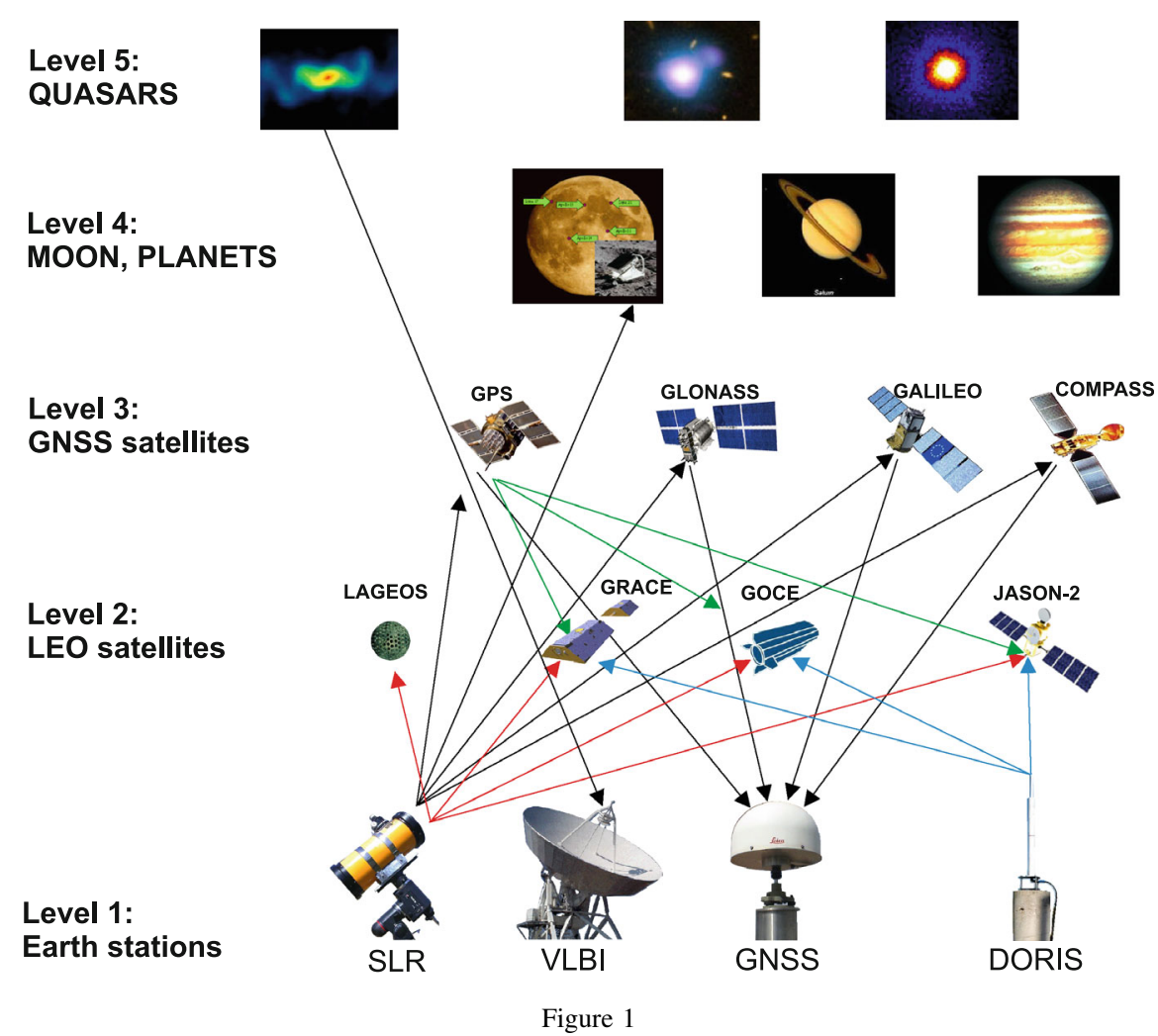

GGOS: An observing system of layered infrastructure (based on the Fig. 9.2. and Fig. 9.9. in chapter 9 (RothACHER et al., 2009) of PlAG and Pearlman (2009) (c) Springer-Verlag Berlin Heidelberg 2009)

common observations and form an integrated observation platform. Within the framework of the GGOS (Fig. 1) the geodetic space techniques (SLR, GPS, DORIS, InSAR, Altimetry), the gravimetric space techniques (orbit analysis, high-low satellite-tosatellite tracking, low-low satellite-to-satellite tracking, satellite gradiometry), the geodetic space techniques delivering earth rotation (VLBI, SLR, GNSS as well as the relevant astrometric techniques and missions) and the atmospheric sounding techniques (GNSS-to-LEO and GNSS to Earth) are integrated.

The pillar of this integration in GGOS is the existing global ground geodetic network used in realizations of the Terrestrial Reference System (TRS) (Plag and Pearlman, 2009). The following concepts have to be considered before definition of the TRS:

- The reference system is ideal and conventional, in addition it has specified mathematical and physical properties. It can be specified as a set of findings and recommendations together with a description of models needed to define the origin, the scale (metric) and the orientation axis, and the variability of those parameters over time.

- The reference frame is a practical materialization of the system by means of coordinates of reference points obtained by using observations.

- The coordinate system is a system which uses one or more numbers or coordinates to uniquely determine the position of a point or other geometric element.

The Terrestrial Reference System (TRS) is a spatial reference system co-rotating with the Earth in its diurnal motion in space and provides a set of coordinates of some points located at or above the Earth's surface. Figure 2 shows the geometric interpretation of TRS.

Two coordinate frames are commonly used: a rotating system fixed to the Earth's surface (terrestrial; used for most practical applications) and an essentially inertial system fixed to the stars (celestial; 


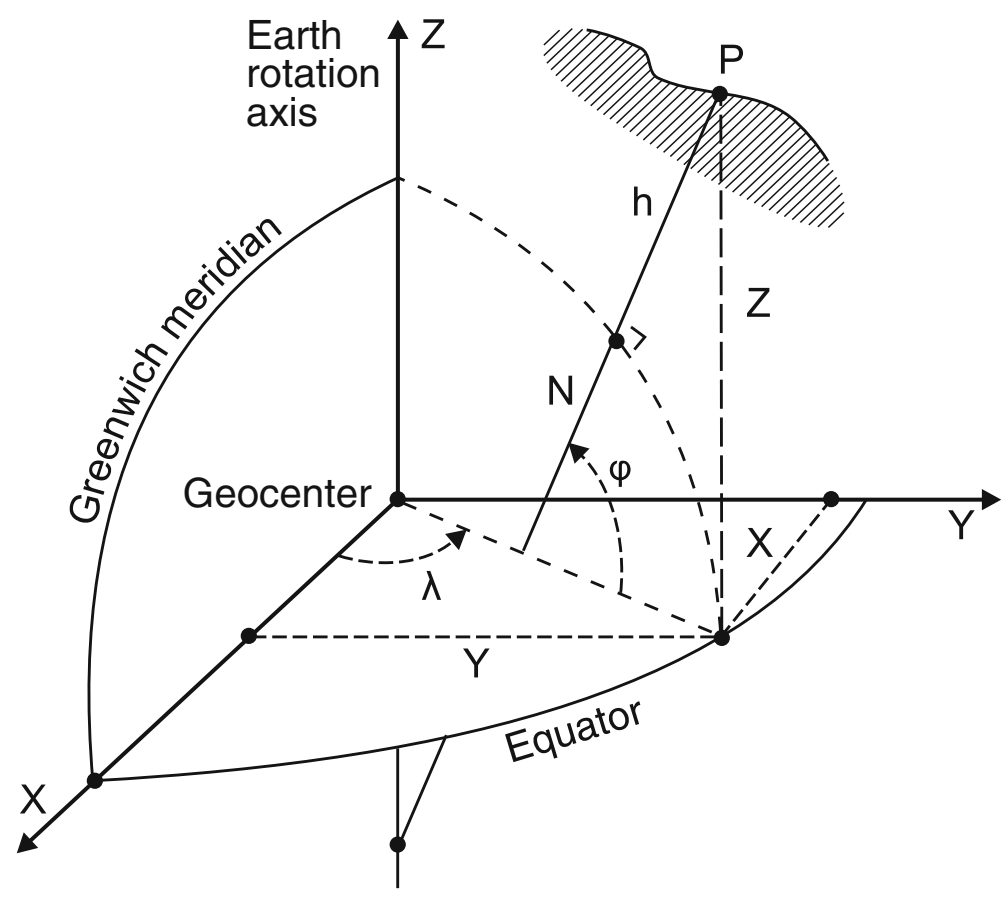

Figure 2

Terrestrial reference system

where dynamical equations of motion can be solved). The celestial reference frame was historically specified by the equator, the ecliptic and the pole of the Earth rotation and was realized by the two-dimensional coordinates of a large number of stars. The present-day International Celestial Reference Frame (ICRF) is defined by the coordinates of a much smaller set of essentially stationary quasars which have positions that are far better known (Altamimi et al. 2001).

In the past, the terrestrial reference frame was realized mostly through national conventions. The International Latitude Service (ILS) formed in 1895 and of itself stressed the development of the first international group of globally distributed stations to define and monitor the evolution of the reference frame. Moreover in 1962, this group evolved into the much broader International Polar Motion Service (IPMS). The establishment of the International Earth Rotation Service (IERS) in 1988 by the International Astronomical Union and the International Union of Geodesy and Geophysics shifted the responsibility for establishing and maintaining both frames to a single international authority. It was the genesis of the International Terrestrial Reference Frame (ITRF) (Altamimi et al., 2001). In 2003 IERS was renamed to be the International Earth Rotation and Reference Systems Service.

The primary objectives of the IERS are to serve astronomical, geodetic and geophysical communities by providing the following (http://www.iers.org):

- The International Celestial Reference System (ICRS) and its realization, the ICRF.

- The International Terrestrial Reference System (ITRS) and its realization, the ITRF.

- Earth orientation parameters (EOP) required to study Earth orientation variations and to transform between the ICRF and the ITRF.

- Geophysical data to interpret time/space variations in the ICRF, ITRF or earth orientation parameters, and model such variations.

- Standards, constants and models (i.e., conventions) encouraging international adherence.

In the frame of TRS definition and realization, there are the very important EOP, which describe the irregularities of the Earth's rotation. The EOP are the parameters which provide the rotation of the ITRS 
to the ICRS as a function of time and contain (Seidelmann, 1982):

- Universal time. Universal time (UT1) is the time of the earth clock, which performs one revolution in about $24 \mathrm{~h}$. It is practically proportional to the sidereal time. The excess revolution time is called length of day (LOD).

- Coordinates of the pole. Coordinates of the pole $\mathrm{x}$ and $y$ are the coordinates of the Celestial Intermediate Pole (CIP) relative to the IRP, the IERS Reference Pole. The CIP differs from the instantaneous rotation axis by quasi-diurnal terms with amplitudes under 0.01 (see SeIDELmann, 1982). The $x$ axis is in the direction of IRM, the IERS Reference Meridian and whose y-axis is in the direction of $90^{\circ}$ East longitude.

- Celestial pole offsets. Celestial pole offsets are described in the IAU Precession and Nutation models. The observed differences with respect to the conventional celestial pole position defined by the models are monitored and reported by the IERS.

The ITRS and EOP are based on the geodetic space techniques such as (Altamimi et al., 2011; Petit and Luzum, 2010):

- Very Long Baseline Interferometry (VLBI),

- Satellite Laser Ranging (SLR),

- Lunar Laser Ranging (LLR),

- Global Navigation Satellite Systems (GNSS),

- Doppler Orbitography and Radiopositioning Integrated by Satellite (DORIS).

The Technique Centres of the above geodetic space techniques are autonomous independent services, which cooperate with the IERS.

The Very Long Baseline Interferometry (VLBI) observations are provided in the frame of the IERS by the International VLBI Service for Geodesy and Astrometry (IVS) (Schlüter and BeHRend, 2007). Figure 3 show a map of the VLBI stations (ivscc.gsfc.nasa.gov).

The VLBI technique is instrumental in establishing and maintaining the conventional celestial reference frame, called the ICRF (SCHUH and BEHREND, 2012). The actual ICRF realization called ICRF2 contains 295 extragalactic radio sources (see Fig. 4).
The IVS provides high accuracy and unique products for the realization and maintenance of the celestial and terrestrial reference frames, ICRF and ITRF, as well as for the EOP (SCHLÜTER and BEHREND, 2007).

The Satellite Laser Ranging (SLR) and the Lunar Laser Ranging (LLR) observations are provided in the frame of IERS by the International Laser Ranging Service (ILRS) (PeARlman et al., 2002). The International Laser Ranging Service (ILRS) was established in September 1998 as a service within the IAG to support programs in geodetic, geophysical and lunar research activities and to provide data products to the IERS in support of its prime objectives (Pearlman et al., 2005). Figure 5 shows the map of SLR and LLR stations (ilrs.gsfc.nasa.gov).

The SLR is sensitive to the location of the Earth's centre of mass. Products derived from those SLR observations include precise satellite ephemerides, station positions and velocities of sites in the ILRS network as well as Earth Orientation Parameters (EOP) (PEARLMAn et al., 2005).

The International GNSS Service (IGS) was formally recognized in 1993 by the IAG, and began routine operations on January 1st, 1994, providing GPS orbits, tracking data, and other data products in support of geodetic and geophysical research. Since June 1992, the IGS, originally known as the International GPS Service for Geodynamics, from 1999 simply as the International GPS Service, and finally since March 2005 as the International GNSS Service, has been providing precise GPS satellite orbit and clock corrections, along with other products, freely available for the public (Dow et al., 2009). The IGS is an international activity involving more than 200 participating organizations from over 80 countries (Beutler et al., 2009). Figure 6 shows the map of IGS stations (440 stations and 367 active stations as of 02 Dec 2012: http://igscb.jpl.nasa.gov).

The IGS together with the IERS pioneered the development of modern geodetic services in IAG. The IGS continues its mission to provide the highestquality GNSS data and products in support of the terrestrial reference frame; Earth observations and research; positioning, navigation and timing; and other applications that benefit society (Dow et al., 2009). 


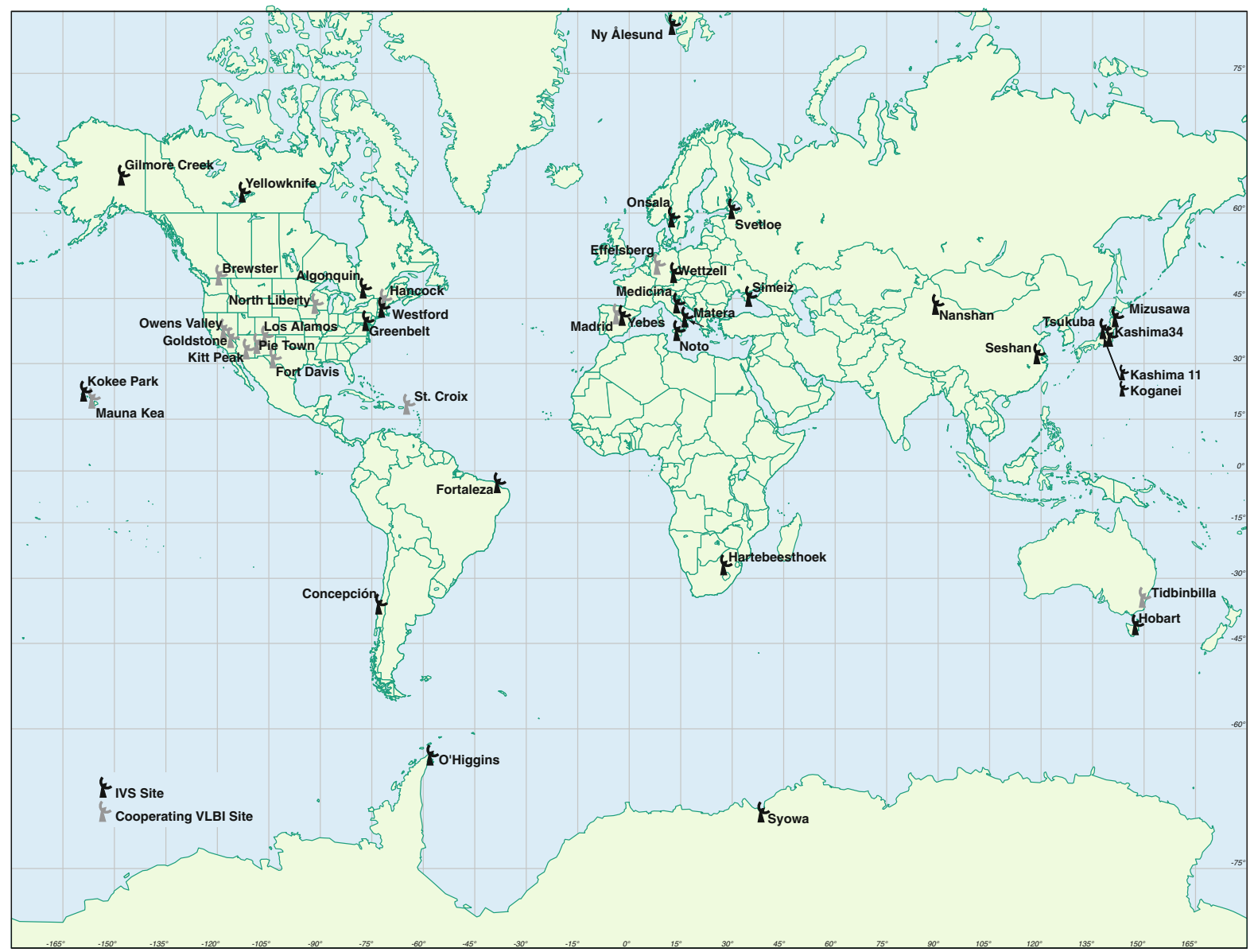

Figure 3

IVS network stations map (With kind permission from: SCHLÜTER and BEHREND (2007), p. 380 (c) Springer-Verlag 2007)

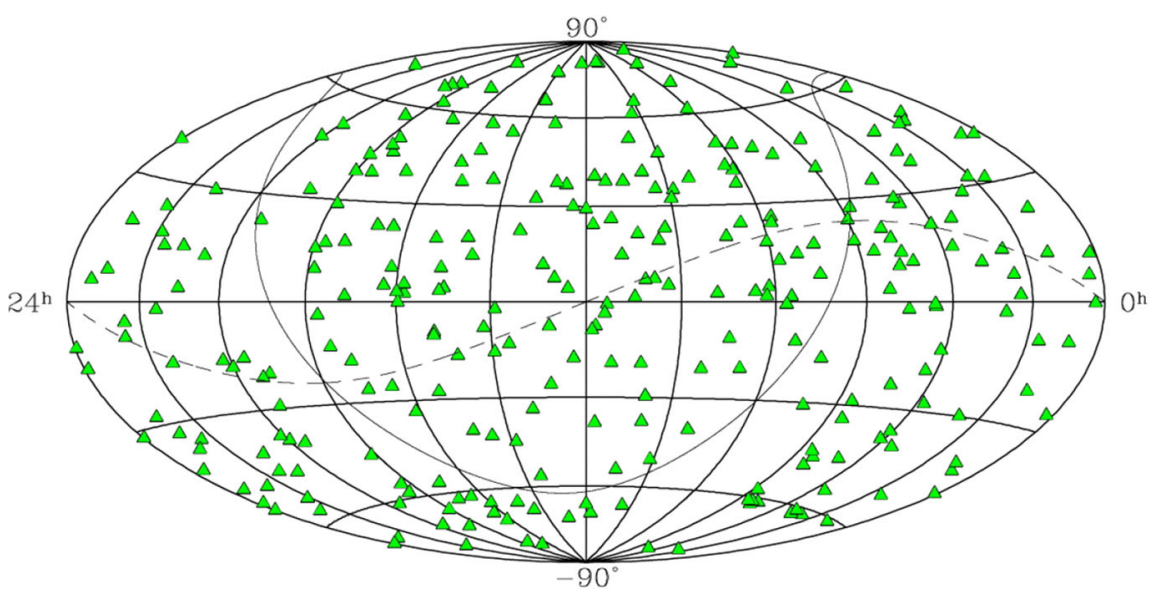

Figure 4

A sky map of the 295 defining radio sources of ICRF2 based on VLBI observations [With kind permission from: SCHUH and BEHREND (2012), p. 71 (c) Elsevier 2012] 


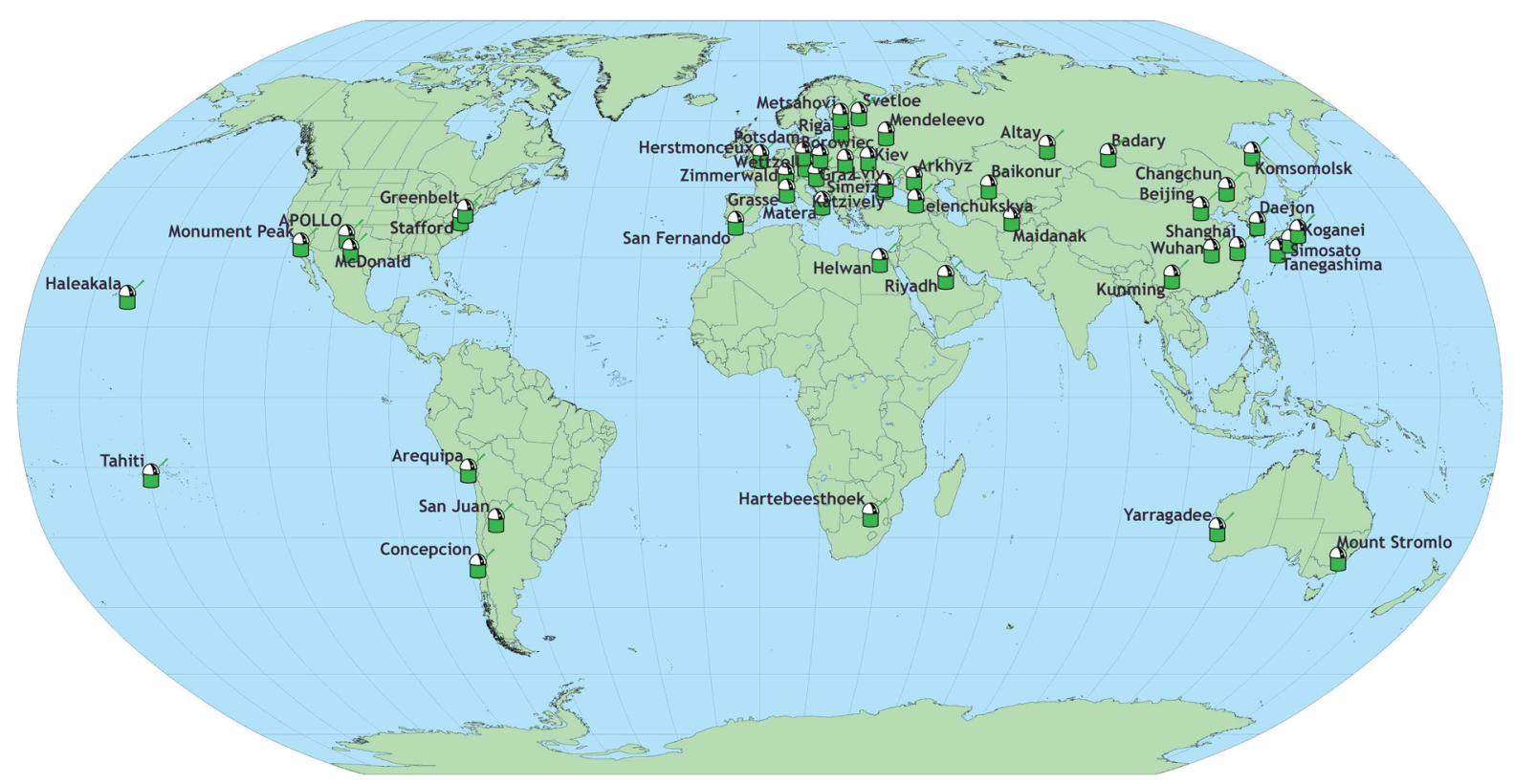

Figure 5

ILRS network stations map (With kind permission from Carey Noll, source http://ilrs.gsfc.nasa.gov/network/stations/index.html (PEARLMAN et al., 2005)

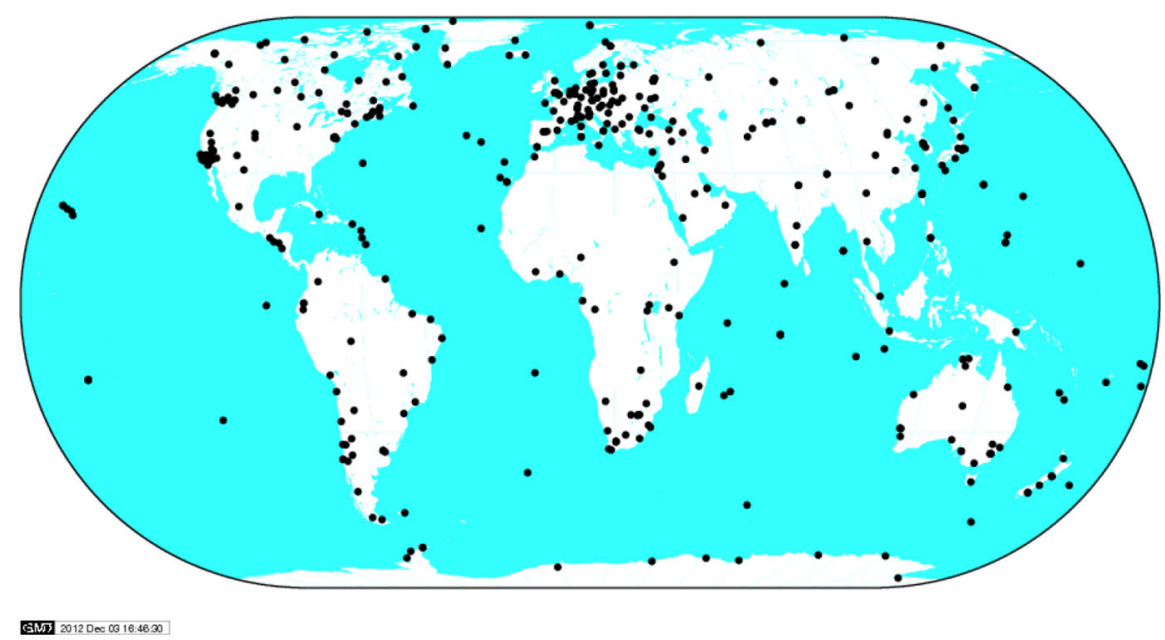

Figure 6

Global distribution of stations of the IGS network (igscb.jpl.nasa.gov, With kind permission from: Dow et al., (2009), p. 192 (c) SpringerVerlag Berlin Heidelberg 2009)

International DORIS Service (IDS) is an international service which provides a support through DORIS data and products to geodetic, geophysical, and other research and operational activities. Since 1st of July 2003, the International DORIS Service has been officially approved as an IAG Service after the decision of the IAG Executive Committtee at the
IUGG General Assembly in Sapporo (ids-doris.org). As the DORIS network was deployed by a geodetic institution, great care was taken to select an appropriate geographical location that would enable colocation of DORIS stations (Fig. 7) with other space techniques (VLBI, SLR and GNSS) (WILLIS et al., 2010). 


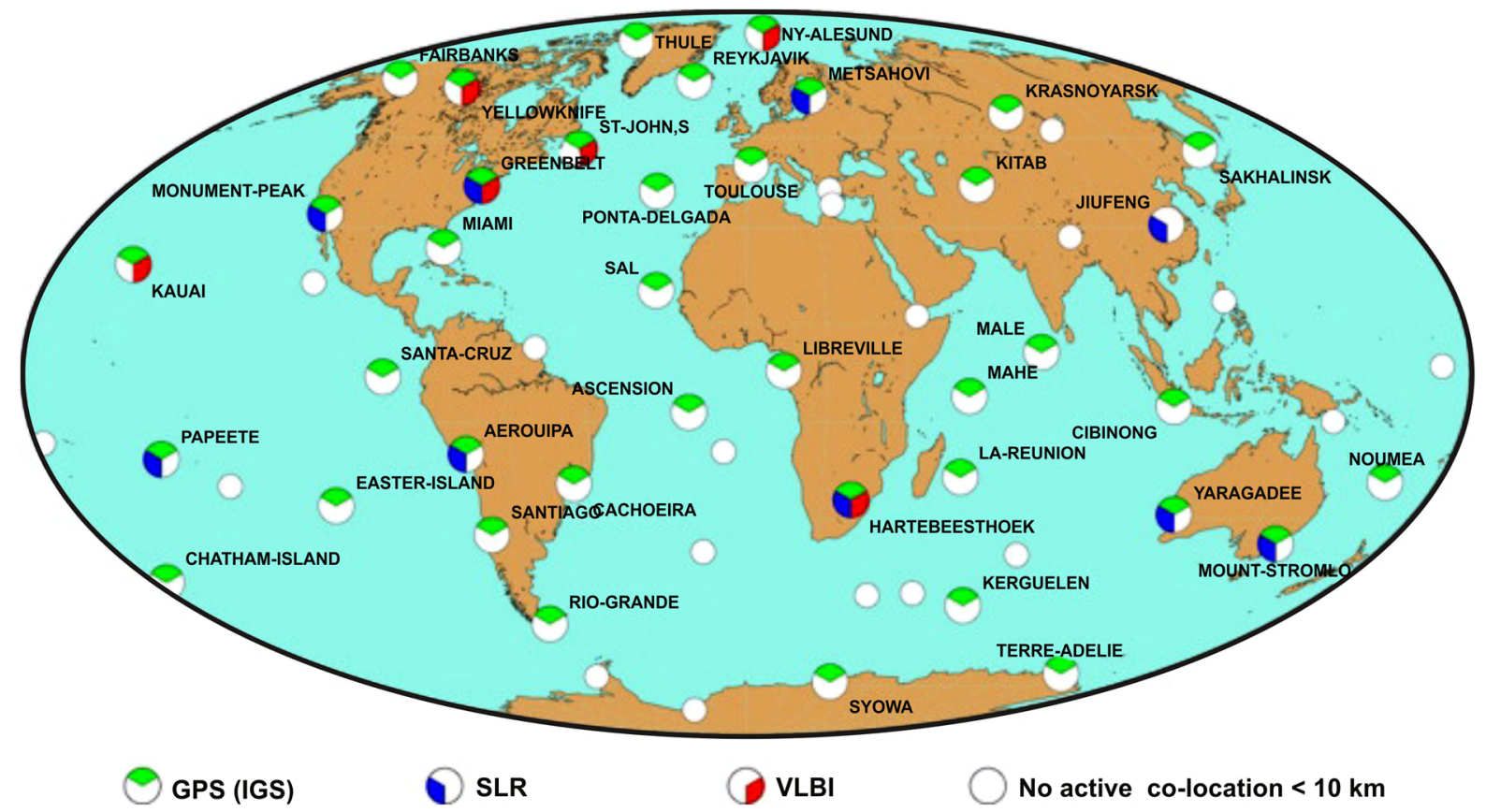

Figure 7

DORIS tracking network with co-locations with other space-geodetic techniques: VLBI, SLR, GNSS (as of May 2009) (With kind permission from: WiLLIS et al. (2010), p. 1412 (c) Elsevier 2010)

Table 1 describes each of the geodetic satellite techniques and their observation methodologies: targets, instrumentation, and resulting measurement (Noll, 2010).

The International Union of Geodesy and Geophysics (IUGG) adopted as TRS the ITRS at its General Assembly in Perugia in 2007, through its Resolution 2 (PetiT and Luzum, 2010).

The regional TRS for Europe named the European Terrestrial Reference System 89 (ETRS89) has been adopted by the IAG Subcommision for the European Reference Frame (EUREF) following its Resolution 1 at the Firenze meeting in 1990 as the European densification of ITRS.

In the year 2000 the Polish government adopted the National Spatial Reference System (PSOP) as binding law on the Polish territory.

The first part of the paper presents the description of the global geodetic reference system, which currently represents ITRS. The second part contains the description of the ETRS89, which is densification of ITRS. The third part was devoted to PSOP existing in
Poland and is currently being implemented. Practically only the GNSS satellite technology has been employed to set up reference system.

\section{The International Terrestrial Reference System and Frame}

The International Union of Geodesy and Geophysics (IUGG) defined by the IUGG resolution No. 2 adopted (in Vienna in 1991) the ITRS. The IERS responsible for implementing the ITRS system was set up in 1987 by the International Astronomical Union (IAU). The current ITRS system was defined by the IERS in the IERS Conventions 2010 (PetiT and Luzum, 2010) in the Chapter 4-Terrestrial Reference System and Frame. The ITRS constitutes a set of prescriptions and conventions together with the modelling required to define origin, scale, orientation and time evolution of a TRS.

The ITRS definition fulfills the following conditions (Petit and Luzum, 2010): 
Table 1

Overview of space geodetic techniques (NoLL, 2010)

\begin{tabular}{|c|c|c|c|}
\hline Technique & Target & Receiver/transmitter & Measurement \\
\hline DORIS & Satellites equipped with DORIS receiver and uplink hardware & $\begin{array}{l}\text { Beacon transmitting } \\
\text { radiofrequency signals }\end{array}$ & $\begin{array}{l}\text { Doppler shift on radiofrequency } \\
\text { signals and phase (new receiver } \\
\text { version only) }\end{array}$ \\
\hline GNSS & $\begin{array}{l}\text { Satellites (GPS, GLONASS, Galileo) equipped with precise } \\
\text { clocks transmitting satellite messages such as ephemeris, } \\
\text { clock offsets, etc. }\end{array}$ & $\begin{array}{l}\text { Dual frequency GNSS } \\
\text { receiver and antenna }\end{array}$ & $\begin{array}{l}\text { Station to satellite pseudorange, } \\
\text { phase delay }\end{array}$ \\
\hline $\begin{array}{l}\text { SLR } \\
\text { LLR }\end{array}$ & Satellites equipped with corner cubes/retroreflectors & $\begin{array}{l}\text { Ground-based short-pulse } \\
\text { laser transmitter }\end{array}$ & $\begin{array}{l}\text { Round-trip pulse time-of-flight } \\
\text { from laser station to satellite }\end{array}$ \\
\hline VLBI & Quasars (microwave frequencies) & $\begin{array}{l}\text { Radio telescope equipped } \\
\text { with } \mathrm{X} \text {-and S-wideband } \\
\text { receivers }\end{array}$ & $\begin{array}{l}\text { Difference in signal arrival times } \\
\text { between two observing antennas }\end{array}$ \\
\hline
\end{tabular}

1. It is geocentric, that the origin is of the center of mass defined for the whole Earth, including oceans and atmosphere.

2. The unit of length is $1 \mathrm{~m} \mathrm{SI}$ (scale consistent with the geocentric coordinate time (TCG)). This scale is consistent with the TCG time coordinate for a geocentric local frame in agreement with IAU and IUGG (1991) resolutions. It is obtained by appropriate relativistic modelling.

3. Its orientation was initially given by the Bureau International de l'Heure (BIH) orientation at 1984.0.

4. The time evolution of the orientation is ensured by using no-net-rotation condition with regards to horizontal tectonic motions over the Earth.

The Terrestrial Reference Frame is defined as the realization of a TRS, through the realization of its origin, orientation axes, scale and their time evolution. We consider here that the realization of a Terrestrial Reference System is achieved by a set of physical points with precisely determined coordinates in a specific coordinate system as a realization.

Realizations of the ITRS are produced by the IAG ITRS Product Center (ITRS-PC) under the name of the ITRF. The ITRF coordinates were obtained by combination of individual TRF solutions computed by IAG International Services analysis centers using the observations of the Space Geodesy techniques: GPS, VLBI, SLR, LLR and DORIS. The ITRF is determined from input SINEX files containing technique-specific station positions and EOPs
The primary realizations of the ITRS are produced by the IERS ITRS Center (ITRS-PC) under the name of the ITRF. Since 1988, the IERS has realized 12 ITRF, viz., ITRF88 to ITRF2008.

The ITRF88 is the realization of ITRS system to the time $t_{0}=1988.0$. The ITRF88 was computed combining mean station positions (without station velocities) of VLBI, LLR and SLR observing networks (only 22 co-located stations) (Fig. 8). The GPS solutions were included for the first time in the ITRF combination in 1991 and DORIS in 1994 (ALtAmimI et al., 2005).

From ITRF88 till ITRF93, the ITRF datum definition can be summarized as follows (PetiT and Luzum, 2010; Boucher and Altamimi, 1996):

- Origin and scale: defined by an average of selected SLR solutions;

- Orientation: defined by successive alignment since BTS (BIH Terrestrial System) 87 whose orientation was aligned to the BIH EOP series. Note that the ITRF93 orientation and its rate were again realigned to the IERS EOP series;

- Orientation time evolution: no global velocity field was estimated for ITRF88, ITRF89 and ITRF90, so the AM0-2 model of Minster and Jordan (1978) was recommended. Starting with ITRF91 and till ITRF93, combined velocity fields were estimated. The ITRF91 orientation rate was aligned to that of the NNR-NUVEL-1 model (Argus and Gordon, 1991) and ITRF92 to NNR-NUVEL-1A, adapted 


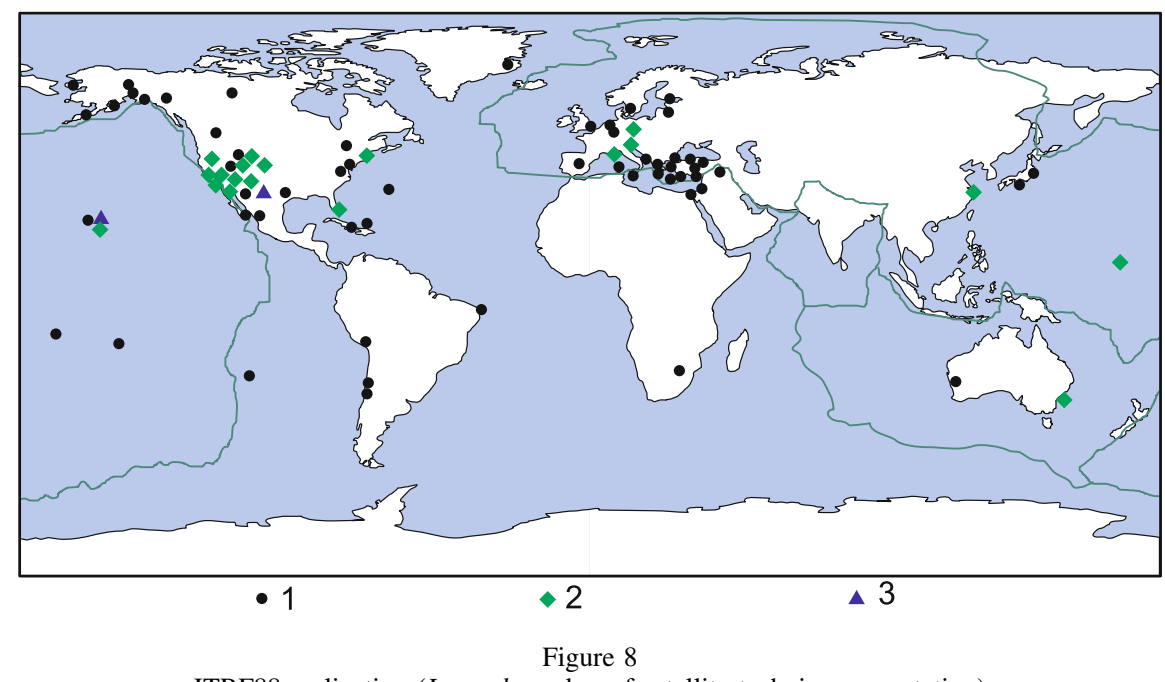

ITRF88 realization (Legend number of satellite techniques on station)

from NNR-NUVEL-1 (DEMETs et al., 1994), while ITRF93 was aligned to the IERS EOP series.

ITRF2008 is the actual realization of the ITRS. The ITRF2008 uses, as the input, the data time series of station positions and Earth Orientation Parameters (EOPs) (Table 2), and has been provided by the Technique Centers (TC) of the four space geodetic techniques (GPS, VLBI, SLR, DORIS). Table 2 summarizes the submitted solutions by the IAG services, specifying the time span, solution type and the constraints applied by the TCs as well as the estimated EOP) (АLтамімі et al., 2011).

The submitted VLBI solution involves more than 4000 session-wise SINEX files spanning the entire VLBI observation history (BöcKMANN et al., 2010). The SLR solution covers the observation time period between 1983.0 and 2009.0 (SLR observations started in 1976 with the launch of the LAGEOS satellite), and comprises fortnightly SINEX files, with polar motion and Length of Day (LOD) estimated each three days between 1983.0 and 1993.0 and weekly SINEX files with daily polar motion and LOD estimates afterwards (PAvLIS et al., 2010). The GPS submitted solution represents a large part of the first reprocessed solution by the IGS and covers the time period between 1997.0 and 2009.5 (FERLAND, 2010; Ferland and Piraszewski, 2009). The seven ACs provided DORIS observations time series covering the full range of data history, from all available satellites equipped with a DORIS receiver (except Jason-2) (VALETte et al., 2010).

The ITRF2008 network comprises 934 stations located at 580 sites, with 463 sites in the northern hemisphere and 117 in the southern hemisphere. The ITRF2008 combination involves 84 co-location sites with two or more technique instruments operating and for which local ties are available (Fig. 9) (Altamimi et al., 2011).

The ITRF2008 is specified by the following frame parameters (Petit and Luzum, 2010):

Table 2

Summary of submitted solutions to ITRF2008 (ALTAMIMI et al., 2011)

\begin{tabular}{lllll}
\hline TC & Data-span & Solution type & Constraints & EOPs \\
\hline IVS & $1980.0-2009.0$ & Normal equation & None & Polar motion, rate, LOD, UT1-UTC \\
ILRS & $1983.0-2009.0$ & Variance-covariance & Loose & Polar motion, LOD \\
IGS & $1997.0-2009.5$ & Variance-covariance & Minimum & Polar motion, rate, LOD \\
IDS & $1993.0-2009.0$ & Variance-covariance & Minimum & Polar motion, rate, LOD \\
\hline
\end{tabular}




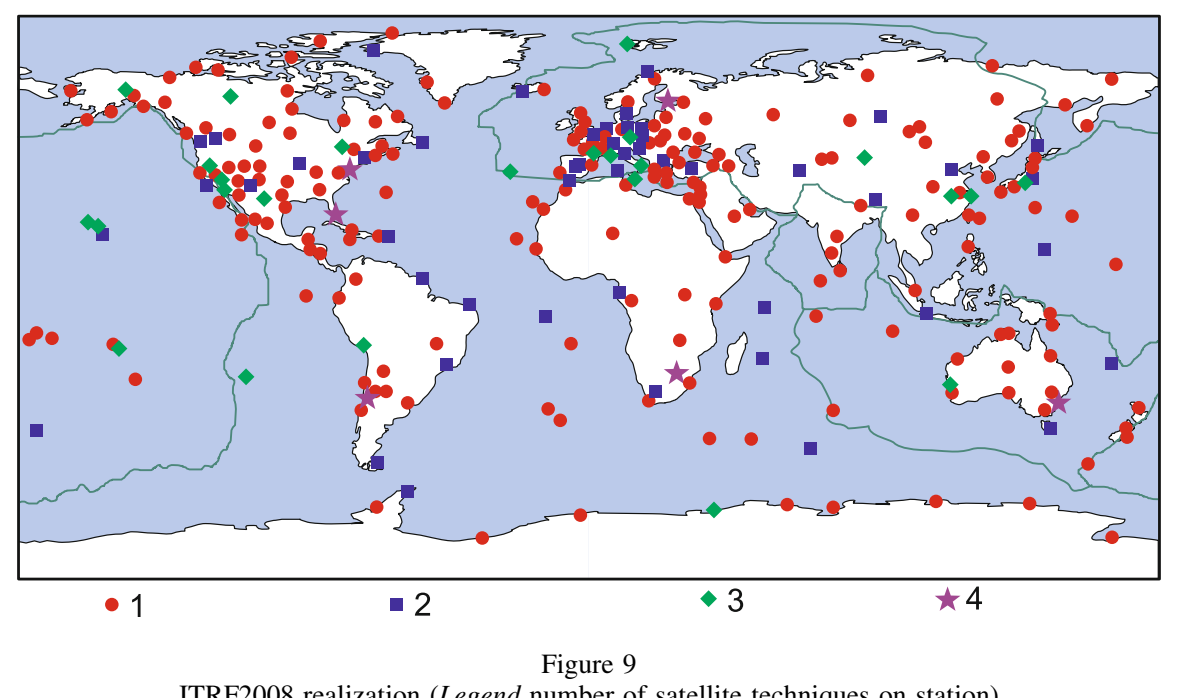

ITRF2008 realization (Legend number of satellite techniques on station)

- Origin: The ITRF2008 origin is defined in such a way that there are zero translation parameters at epoch 2005.0 and zero translation rates with respect to the ILRS SLR time series.

- Scale: The scale of the ITRF2008 is defined in such a way that there is a zero scale factor at epoch 2005.0 and a zero scale rate with respect to the mean scale and scale rate of VLBI and SLR time series.

- Orientation: The ITRF2008 orientation is defined in such a way that there are zero rotation parameters at epoch 2005.0 and zero rotation rates between ITRF2008 and ITRF2005. Those two conditions are applied over a set of 179 reference stations located at 131 sites, including 107 GPS, 27 VLBI, 15 SLR and 12 DORIS sites.

The criteria that were retained for site selection are (Аlтамімі et al., 2011):

1. Continuously observed during at least 3 years;

2. Located on rigid plates and far away from deforming zones;

3. Velocity formal error (as result of ITRF combination) better than $3 \mathrm{~mm} /$ years;

4. Velocity residuals less than $3 \mathrm{~mm} /$ years for at least three different solutions.

Stations that meet those criteria are in the group of stations and are used in the estimation of the transformation parameters between ITRS realizations.
The ITRS realization consists of the stations together with the positions at epoch $t_{0}, X_{Y Y}^{I}\left(t_{0}\right)$ and the velocities $\dot{X}_{Y Y}^{I}$. The position of a station at epoch $t$ is computed using equation (Boucher and Altamimi, 2011):

$$
X_{Y Y}^{I}\left(t_{c}\right)=X_{Y Y}^{I}\left(t_{0}\right)+\dot{X}_{Y Y}^{I} \cdot\left(t_{c}-t_{0}\right) .
$$

The conversion between different realizations (for example, $A$ and $B$ ) the following transformation formula has been applied (Boucher and Altamimi, 2011):

$$
\begin{aligned}
\left(\begin{array}{c}
X_{B} \\
Y_{B} \\
Z_{B}
\end{array}\right)= & \left(\begin{array}{c}
X_{A} \\
Y_{A} \\
Z_{A}
\end{array}\right)+\left(\begin{array}{c}
T x \\
T y \\
T z
\end{array}\right) \\
& +\left(\begin{array}{ccc}
D & -R z & R y \\
R z & D & -R x \\
-R y & R x & D
\end{array}\right) \times\left(\begin{array}{c}
X_{A} \\
Y_{A} \\
Z_{A}
\end{array}\right),
\end{aligned}
$$

where the transformation parameters are linearly dependent of time.

Therefore, the transformation parameter $P$, is noted as:

$$
P_{A, B}(t)=P_{A, B}\left(t_{0}\right)+\dot{P}_{A, B} \times\left(t-t_{0}\right),
$$

where $t_{0}$ is the reference epoch and $\dot{P}$ that parameter rate of change.

The transformations parameters between ITRF2008 and previous ITRS realizations are presented in Table 3. 
Table 3

Transformation parameters from ITRF2008 to past ITRFs (http://itrf.ensg.ign.fr/doc_ITRF/Transfo-ITRF2008_ITRFs.txt)

\begin{tabular}{|c|c|c|c|c|c|c|c|c|}
\hline $\begin{array}{l}\text { Solution } \\
\text { Units } \\
\text { Rates } \\
\text { Units }\end{array}$ & $\begin{array}{l}\text { Tx } \\
(\mathrm{mm}) \\
\dot{T x} \\
(\mathrm{~mm} / \text { years })\end{array}$ & $\begin{array}{l}\text { Ty } \\
(\mathrm{mm}) \\
\dot{T y} \\
\text { (mm/years) }\end{array}$ & $\begin{array}{l}\mathrm{Tz} \\
(\mathrm{mm}) \\
\dot{T} z \\
\text { (mm/years) }\end{array}$ & $\begin{array}{l}\mathrm{D} \\
(\mathrm{ppb}) \\
\dot{D} \\
\text { (ppb/years) }\end{array}$ & $\begin{array}{l}\mathrm{Rx} \\
(.001 ") \\
\dot{R x} \\
(.001 " / \text { years })\end{array}$ & $\begin{array}{l}\text { Ry } \\
(.001 ") \\
\dot{R y} \\
(.001 " / \text { years })\end{array}$ & $\begin{array}{l}\mathrm{Rz} \\
(.001 ") \\
\dot{R} z \\
(.001 " / \text { years })\end{array}$ & $t_{0}$ \\
\hline ITRF2005 & -2.0 & -0.9 & -4.7 & 0.94 & 0.00 & 0.00 & 0.00 & 2000.0 \\
\hline Rates & 0.3 & 0.0 & 0.0 & 0.00 & 0.00 & 0.00 & 0.00 & \\
\hline ITRF2000 & -1.9 & -1.7 & -10.5 & 1.34 & 0.00 & 0.00 & 0.00 & 2000.0 \\
\hline Rates & 0.1 & 0.1 & -1.8 & 0.08 & 0.00 & 0.00 & 0.00 & \\
\hline ITRF97 & 4.8 & 2.6 & -33.2 & 2.92 & 0.00 & 0.00 & 0.06 & 2000.0 \\
\hline Rates & 0.1 & -0.5 & -3.2 & 0.09 & 0.00 & 0.00 & 0.02 & \\
\hline ITRF96 & 4.8 & 2.6 & -33.2 & 2.92 & 0.00 & 0.00 & 0.06 & 2000.0 \\
\hline Rates & 0.1 & -0.5 & -3.2 & 0.09 & 0.00 & 0.00 & 0.02 & \\
\hline ITRF94 & 4.8 & 2.6 & -33.2 & 2.92 & 0.00 & 0.00 & 0.06 & 2000.0 \\
\hline Rates & 0.1 & -0.5 & -3.2 & 0.09 & 0.00 & 0.00 & 0.02 & \\
\hline ITRF93 & -24.0 & 2.4 & -38.6 & 3.41 & -1.71 & -1.48 & -0.30 & 2000.0 \\
\hline Rates & -2.8 & -0.1 & -2.4 & 0.09 & -0.11 & -0.19 & 0.07 & \\
\hline ITRF92 & 12.8 & 4.6 & -41.2 & 2.21 & 0.00 & 0.00 & 0.06 & 2000.0 \\
\hline Rates & 0.1 & -0.5 & -3.2 & 0.09 & 0.00 & 0.00 & 0.02 & \\
\hline ITRF91 & 24.8 & 18.6 & -47.2 & 3.61 & 0.00 & 0.00 & 0.06 & 2000.0 \\
\hline Rates & 0.1 & -0.5 & -3.2 & 0.09 & 0.00 & 0.00 & 0.02 & \\
\hline ITRF90 & 22.8 & 14.6 & -63.2 & 3.91 & 0.00 & 0.00 & 0.06 & 2000.0 \\
\hline Rates & 0.1 & -0.5 & -3.2 & 0.09 & 0.00 & 0.00 & 0.02 & \\
\hline ITRF89 & 27.8 & 38.6 & -101.2 & 7.31 & 0.00 & 0.00 & 0.06 & 2000.0 \\
\hline Rates & 0.1 & -0.5 & -3.2 & 0.09 & 0.00 & 0.00 & 0.02 & \\
\hline ITRF88 & 22.8 & 2.6 & -125.2 & 10.41 & 0.10 & 0.00 & 0.06 & 2000.0 \\
\hline Rates & 0.1 & -0.5 & -3.2 & 0.09 & 0.00 & 0.00 & 0.02 & \\
\hline
\end{tabular}

The parameters in Table 3 are published in the IERS Technical Notes and Annual Reports http:// www.iers.org/ and available on the official ITRF web page: http://itrf.ensg.ign.fr/doc_ITRF/Transfo-ITRF 2008_ITRFs.txt.

Figures 10 and 11 show the ITRF2008 horizontal and vertical velocity fields with respect to the major plate boundaries (Ацтамім et al., 2011).

The stations velocities presented in Fig. 10 show the tectonic plates movements, with the exception of stations located in the deformation zones. The horizontal and vertical velocities shown in Figs. 10 and 11, obtained from geodetic satellite techniques correspond very well with the geophysical models.

\section{European Geodetic Reference Systems}

The IAG Subcommision for the EUREF, following its Resolution 1 adopted at the Firenze meeting in the 1990 , recommended that the terrestrial reference system to be adopted by EUREF will be coincident with
ITRS at the epoch $t_{0}=1989.0$ and fixed to the stable part of the Eurasian Plate. It will be named ETRS89.

The acceptance of ETRS89 by several communities (civil aviation, industry, national and regional agencies) as the pillar of geo-referencing in Europe is a continuous process. EuroControl (European Agency for Safety of Air navigation) has used ETRS89 for a long time in its technical specifications. There is a recommendation by the European Commission to adopt ETRS89 as the geodetic datum for geo-referenced information and to promote the use of ETRS89 within its member states. Currently, ETRS89 is the regional European system derived from the ITRS and it is used as the coordinate system throughout Europe.

A first measurement campaign covering Western Europe was conducted in 1989, since then other GPS campaigns have been carried out ameliorating the results of previous campaigns and enlarging the territory covered to the Eastern Europe. Practical realization of the geodetic reference system ETRS89 (EUREF-89) was initially provided by 93 stations covering the Western European countries (European 


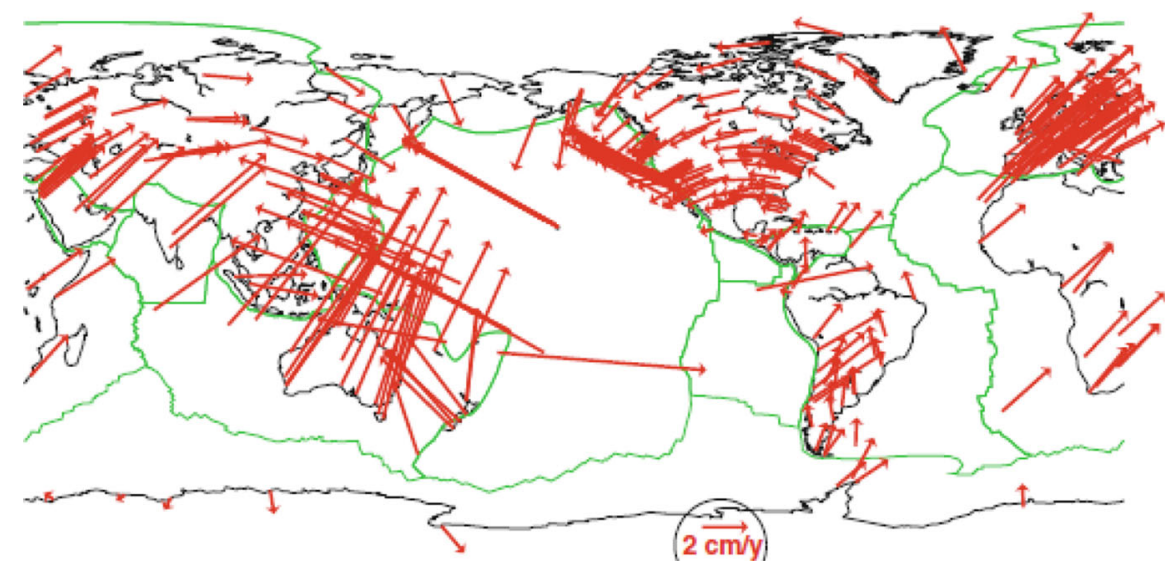

Figure 10

ITRF2008 horizontal velocities with formal error less than $0.2 \mathrm{~mm} /$ years (With kind permission from: Altamimi et al. (2011), p. 470 (c) Altamimi et al. 2011)

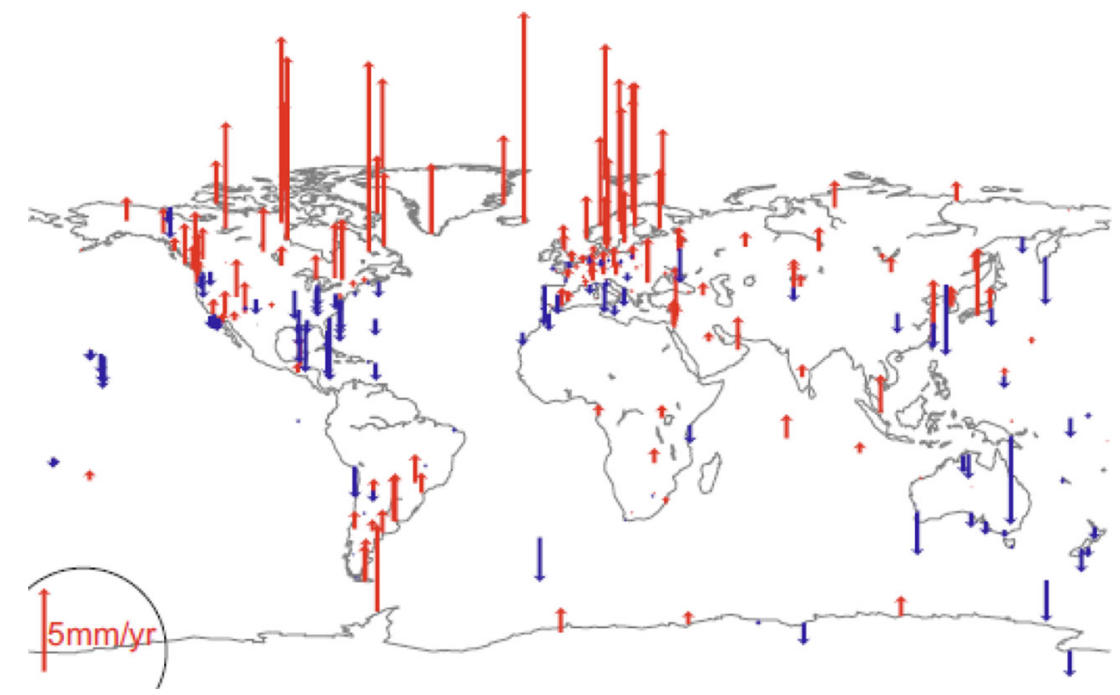

Figure 11

ITRF2008 vertical velocities with formal error less than $0.2 \mathrm{~mm} / \mathrm{years}$. Positive velocities are shown in red and negative in blue (With kind permission from: Ацtamimi et al. (2011), p. 470 (c) Аlтамimi et al. 2011)

Economic Community, the Scandinavian countries and Austria and Switzerland) (Fig. 12). The fundamental stations provided laser observations to satellite targets (SLR/LLR) as well as VLBI readings to quasars. In May 1989, GPS campaign was launched and GPS observations were also used to establish EUREF-89 (SEEGER et al., 1992).

Since 1997, the ETRS89 system has been implemented by the EUREF Permanent Network: http:// www.epncb.oma.be/ (Fig. 13).
The EUREF Permanent Network (EPN) is used today to densify national reference frames (BRUYNINX et al., 2012a, b). The local GNSS networks created for geodynamics studies are also connected to the EPN and/or IGS stations for reference frame realization (Bosy et al., 2009). Based on the series of the regularly updated EPN multi-year position and velocity solution, the EPN stations are categorized taking the station quality and the length of the available observation time span into account 


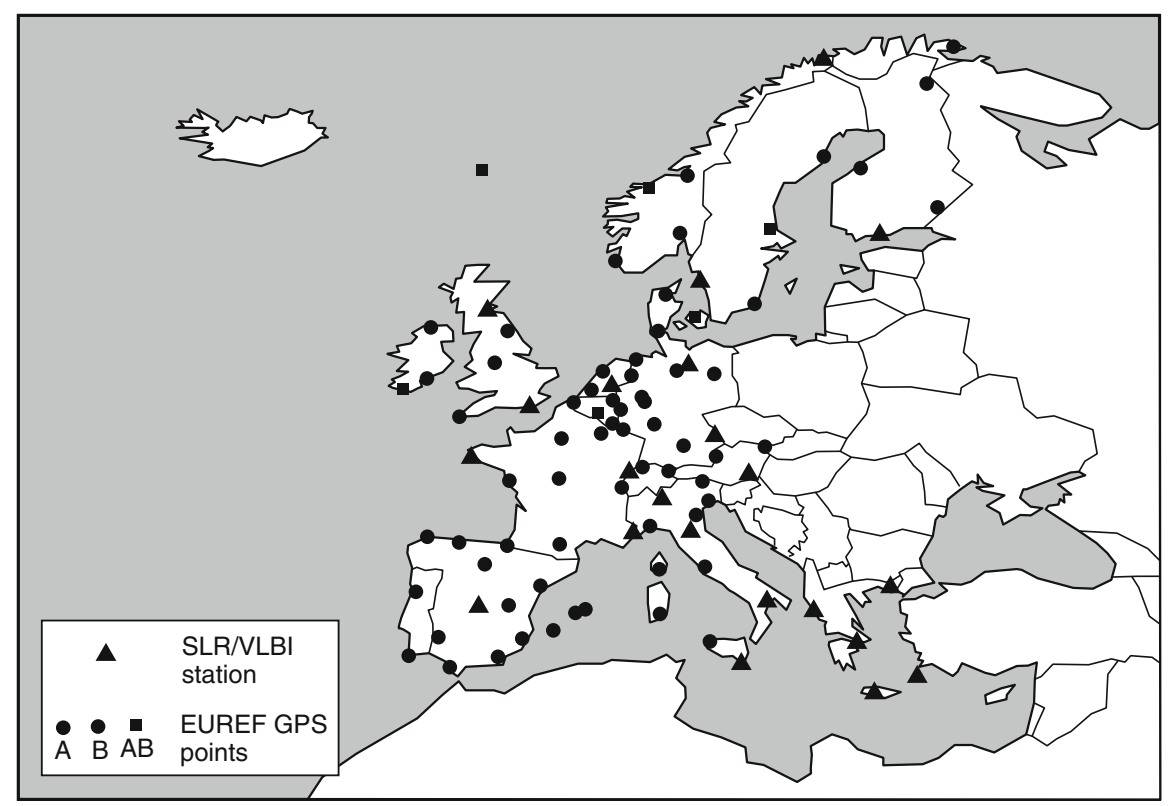

Figure 12

EUREF-89 network stations

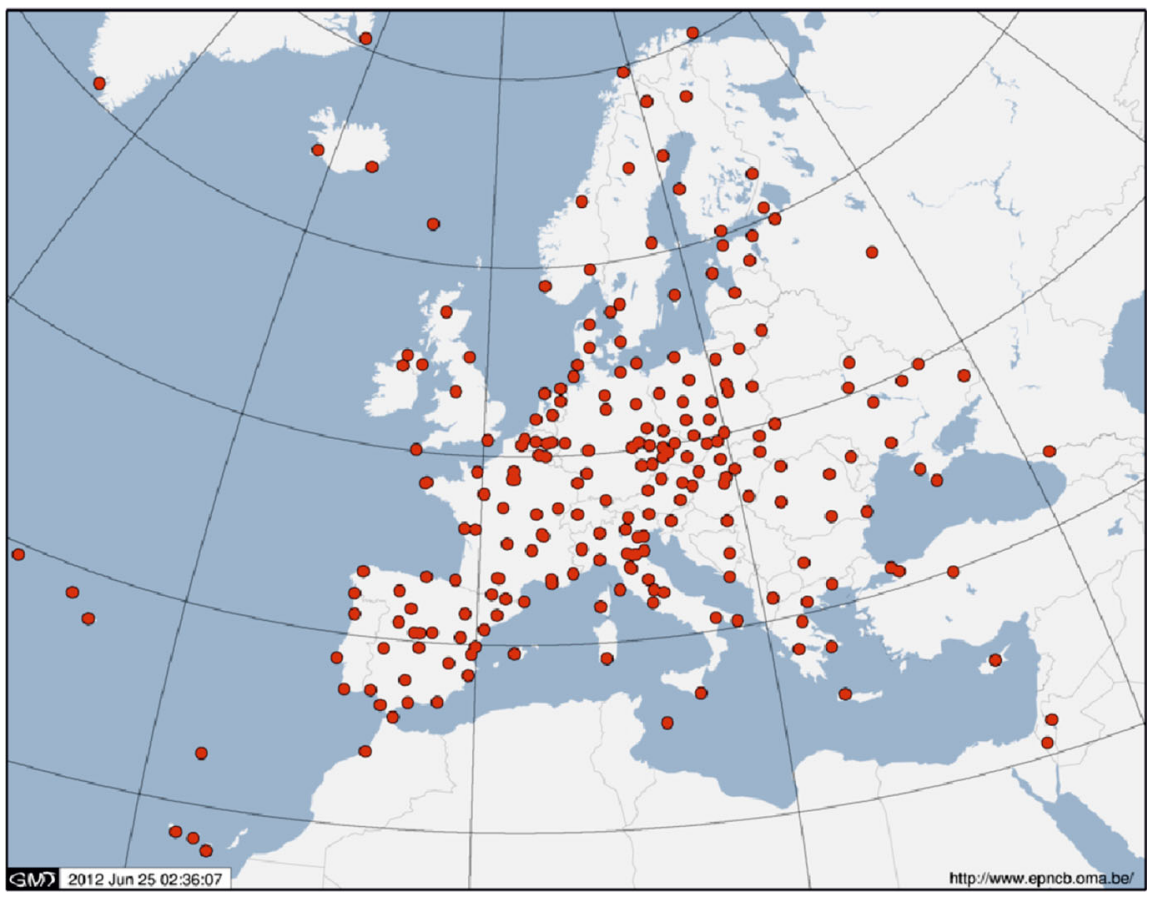

Figure 13

EUREF Permanent Network (With kind permission from C. Bruyninx EPN CB, source http://www.epncb.oma.be)

(KenYeRES, 2009; BRUYNinX et al., 2012a, b). Figure 14 shows the map of categorized stations as in October 28, 2012.
The class A: (green color in Fig. 14) are the stations for which positions have $1 \mathrm{~cm}$ accuracy at all epochs of the time span of the used observations. 


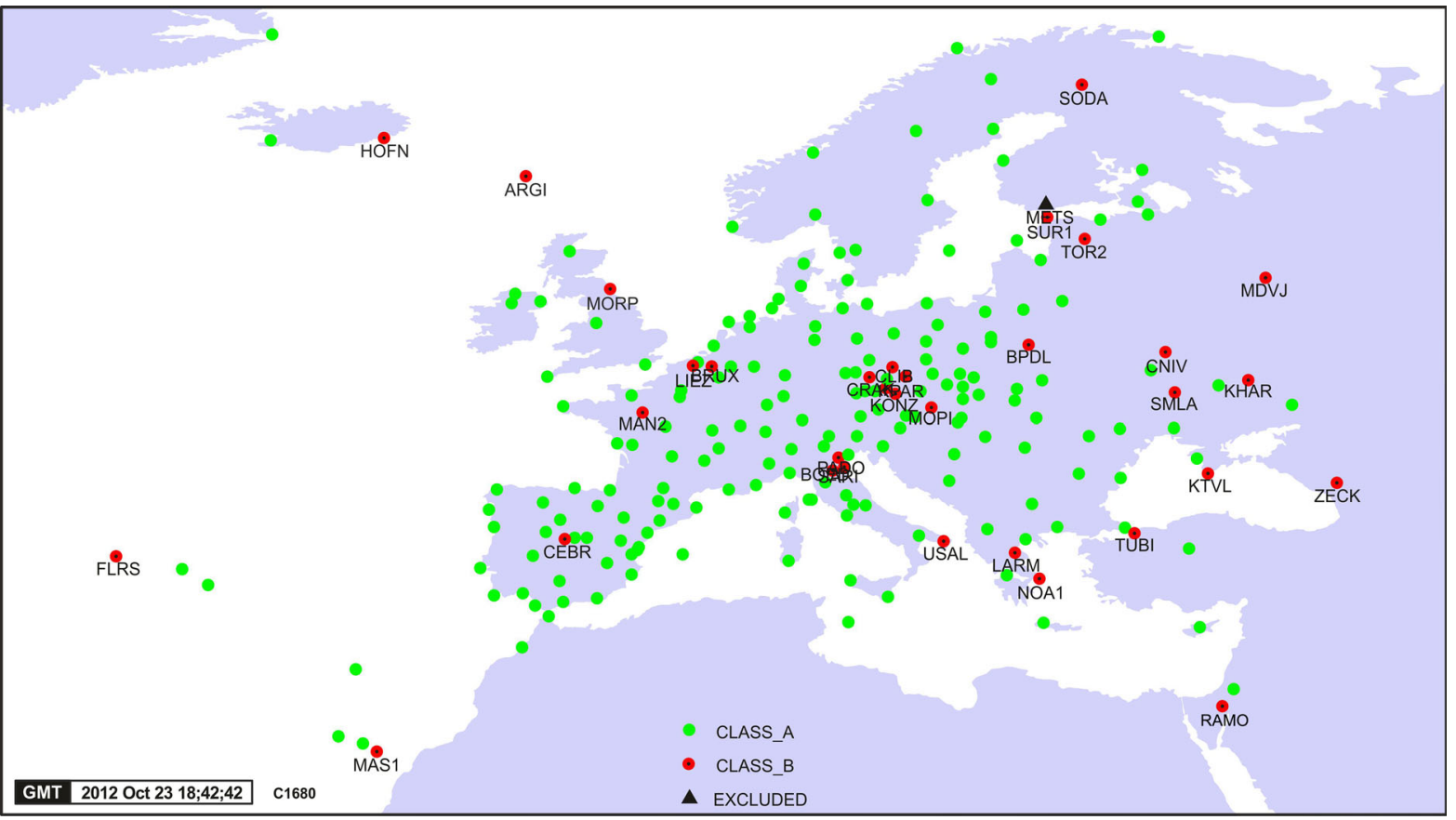

Figure 14

Categorization of the EPN stations (With kind permission from Bruyninx EPN CB, source http://www.epncb.oma.be)
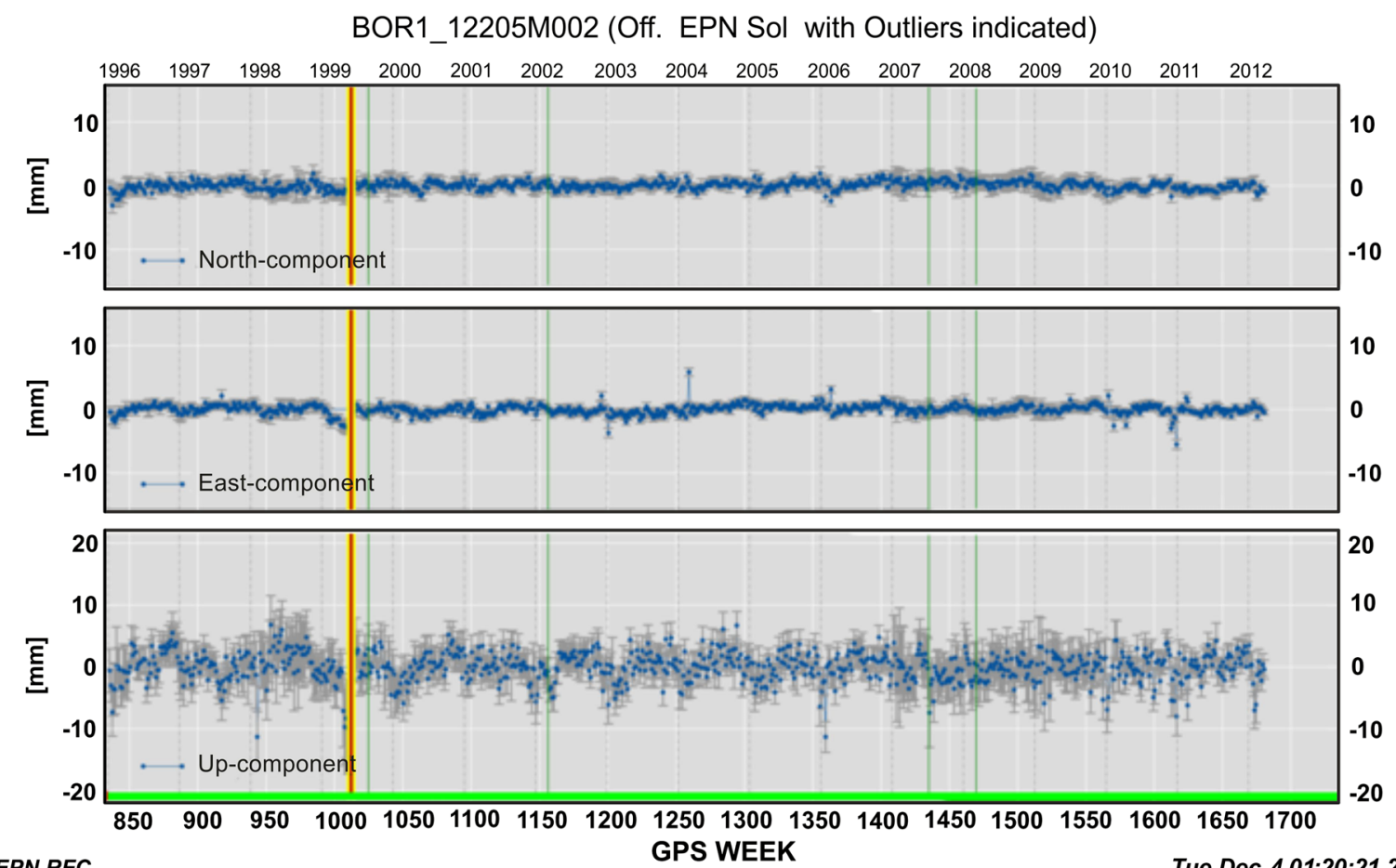

EPN RFC GPS WEEK

Tue Dec 4 01:20:21 2012

Figure 15

Example of station class A: BOR1 (With kind permission from Bruyninx EPN CB, source http://www.epncb.oma.be) 


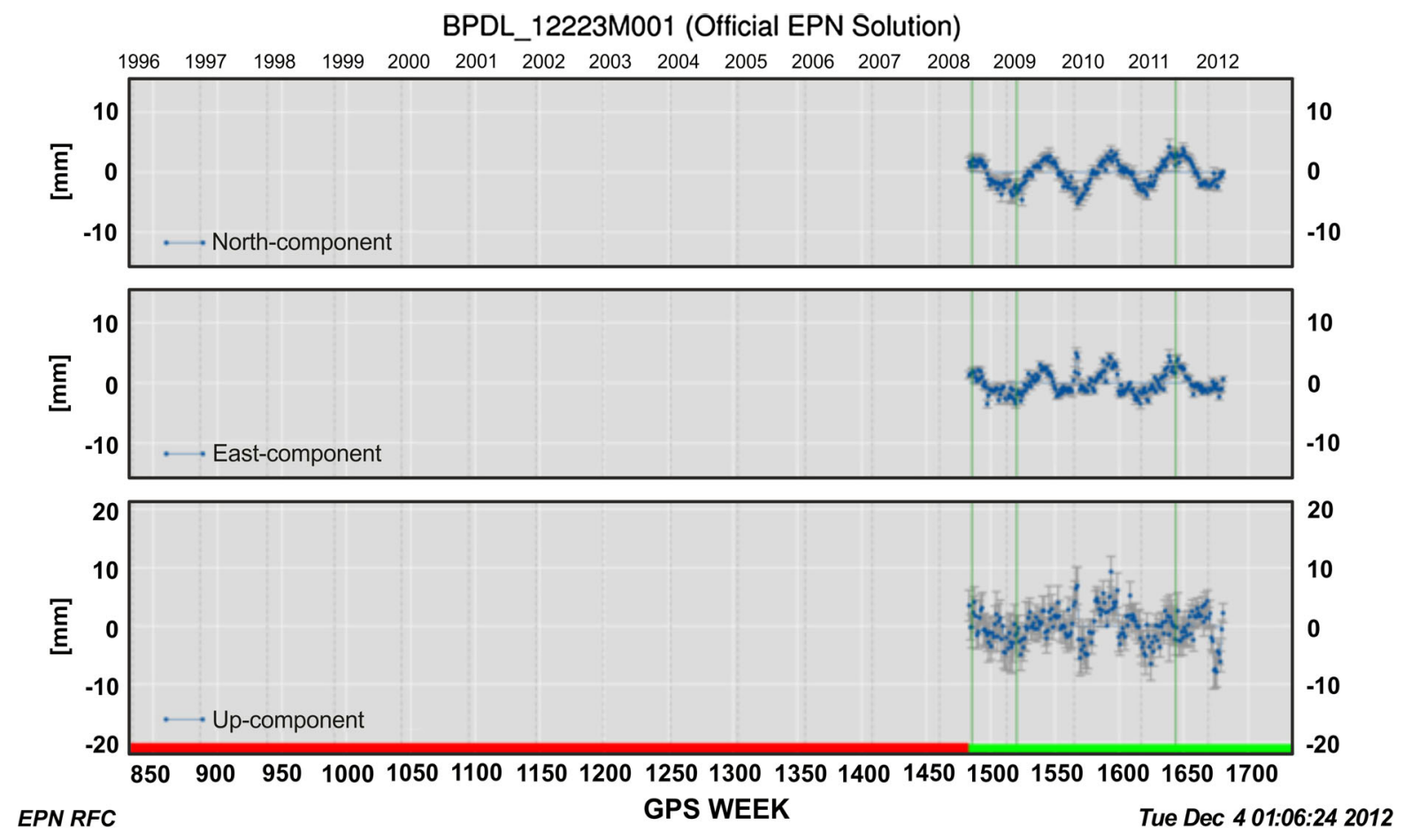

Figure 16

Example of station class B: BPDL (With kind permission from Bruyninx EPN CB, source http://www.epncb.oma.be)

The Fig. 15 shows the example of long term time series of station BOR1, which is in class A and is the reference point of IGS and EPN networks from the start.
The class B: (red color in Fig. 14) are the stations for which positions have $1 \mathrm{~cm}$ accuracy at the epoch of minimal variance of each station. The Fig. 16

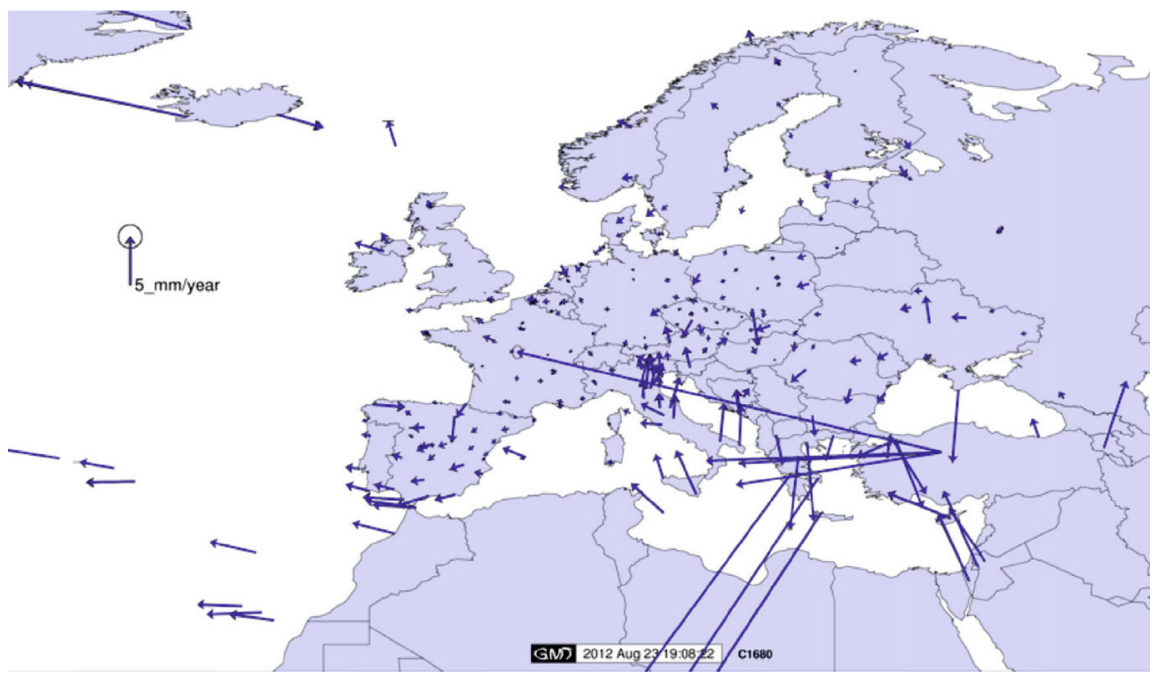

Figure 17

ETRF2000 of EPN stations horizontal velocities (With kind permission from: KeNYERES 2012), (c) Kenyeres (2012) 


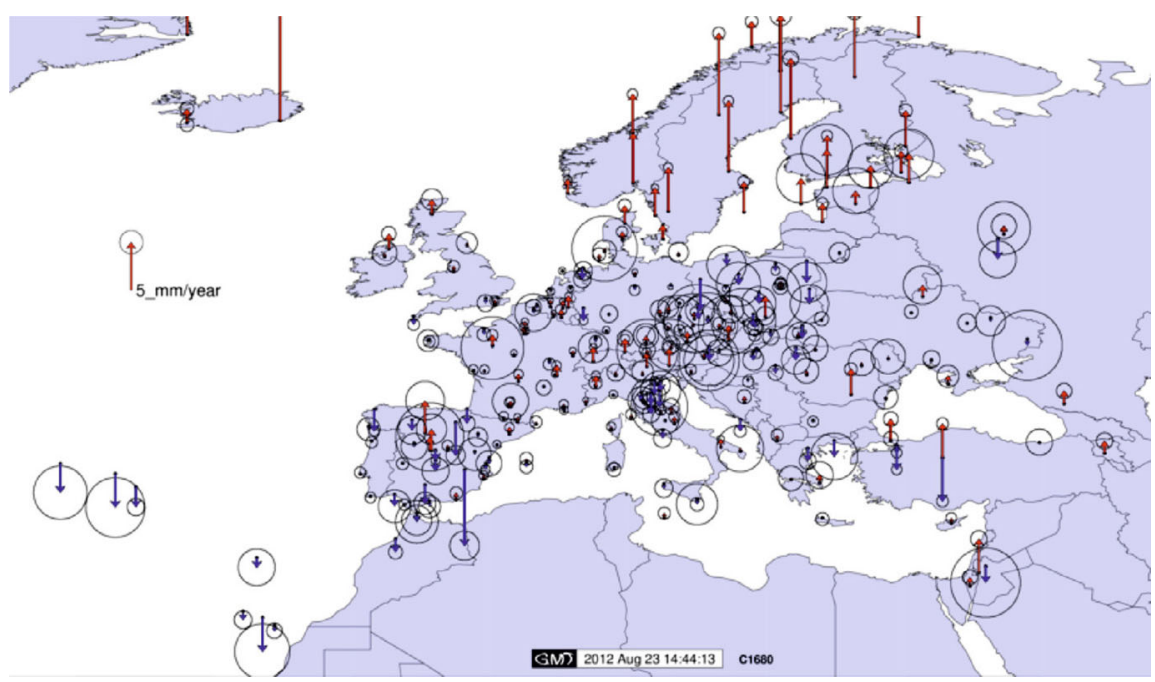

Figure 18

ETRF2000 of EPN stations vertical velocities (With kind permission from: KENYEREs 2012), (c) Kenyeres (2012)

shows the example of a short time series of station BPDL, which is in class B and was included to the EPN network in 2008.

Only Class A stations are suitable as fiducial stations for the densifications of the ETRS89 (BRUYNinX et al., 2012a, b).

The EPN provides regularly updated long-term positions and velocities analysis of the EPN stations based on the combined EPN station solutions. The Figs. 17 and 18 show the horizontal and vertical intraplate (residual) velocities of EPN stations from the long term EPN stations time series analysis (KenYeres, 2012).

The horizontal velocities shown in Fig. 17 are nonzero and not homogenous with distinct local deformation zones. The vertical velocities (Fig. 18) correspond very well with the geophysical models, such as uplift of Fennoscandia.

The EUREF permanent network (EPN) stations stability analysis is crucial for determining the transformation parameters between the golobal (ITRS) and regional or national (e.g., ETRS89) TRS realizations. Specifications for ERTRS89 reference frame fixing for the GNSS campaign and transformation formulas between various realizations of the ETRS89 and ITRS are available from the memo v.8 by Boucher and Altamimi (2011).

The memo (Boucher and Altamimi, 2011) is the official document of EUREF IAG sub-commission and describes the procedures for the implementation of the 1 st level national network and determining the ETRS89 coordinates referred to a central epoch $t_{c}$ of the densification campaign.

The GNSS data are processed in $\operatorname{ITRF}_{Y Y}$ and transformed to ETRS89 realization $\mathrm{ETRF}_{X X}$ at epoch $t_{c}$, according to the procedure described in the memo (Boucher and Altamimi, 2011), and presented schematically in Fig. 19.

The input data are the ITRF and ETRF coordinates and velocities of EPN stations of the reference epoch $t_{0}$. The GNSS data processing is realized at campaign epoch $t_{c}$. According to memo v.8 (BOUCHER and Altamimi, 2011) to compute an EUREF GPS campaign in ETRS89 referred to a central epoch $t_{c}$, the procedure will be (Fig. 20):

1. The coordinates of reference stations in recent $\mathrm{ITRF}_{Y Y}$ are transformed from epoch $t_{0}$ to campaign epoch $t_{c}$ using equation (1). The results are then all consistent with ITRF $_{Y Y}$ at epoch $t_{c}$;

2. Global Navigation Satellite Systems (GNSS) data are processed in $\operatorname{ITRF}_{Y Y}$ (e.g., ITRF2008) and the target ETRS89 frame is $\mathrm{ETRF}_{X X}$ (e.g., ETRF2000). In this case a two-step procedure should be applied:

(a) Transform $\operatorname{ITRF}_{Y Y}$ coordinates at $t_{c}$ into ITRF $_{X X}$ using the IERS/ITRF published values which could be derived from Tables 1 and 2 


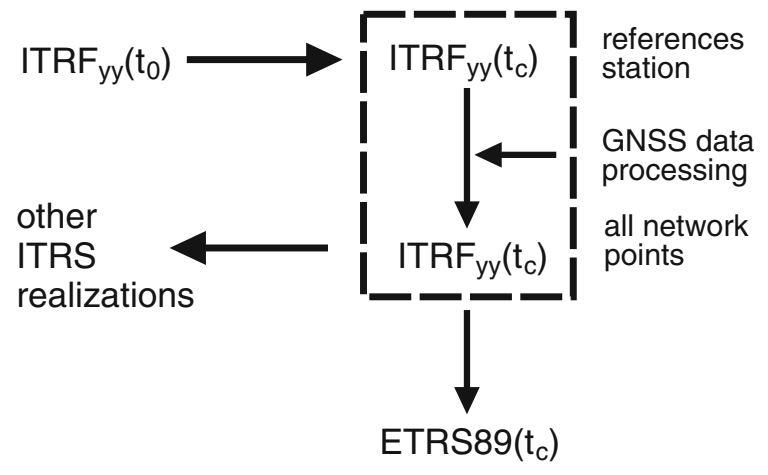

Figure 19

GNSS campaign: ITRF and ETRS89 calculation scheme

\section{$\operatorname{ITRF}_{\mathrm{yy}}\left(\mathrm{t}_{\mathrm{c}}\right)$}

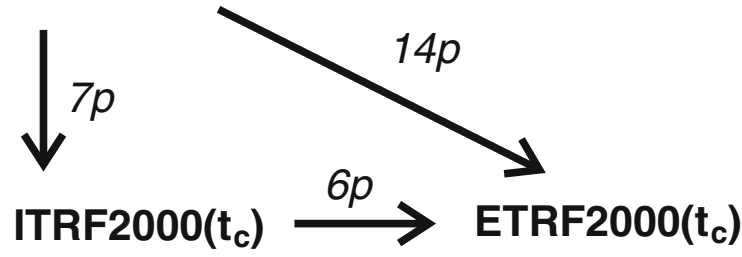

Figure 20

Transformation between $\operatorname{ITRF}_{Y Y}$ and ETRF2000 of this memo v.8 (Boucher and Altamimi, 2011);

(b) Use the formula (4) to transform from ITRF $_{X X}$ to $\mathrm{ETRF}_{X X}$ :

$$
\begin{aligned}
X^{E}\left(t_{c}\right)= & X_{X X}^{I}\left(t_{c}\right)+T_{X X} \\
& +\left(\begin{array}{ccc}
0 & -\dot{R} 3_{X X} & \dot{R} 2_{X X} \\
\dot{R} 3_{X X} & 0 & -\dot{R} 1_{X X} \\
-\dot{R} 2_{X X} & \dot{R} 1_{X X} & 0
\end{array}\right) \\
& \times X_{X X}^{I}\left(t_{c}\right) \cdot\left(t_{c}-1989.0\right) .
\end{aligned}
$$

The estimation procedure of $T_{X X}$ is described in Appendix 1 and of $\dot{R}_{X X}$ in Appendix 2. The corresponding values are listed in Tables 3 and 4 of Appendix 3 of memo v.8 (Boucher and Altamimi, 2011).

3. The above two-step transformation procedure could be performed in one step using 14 transformation parameters between $\operatorname{ITRF}_{Y Y}$ (e.g., ITRF2008) and ETRF $_{X X}$ (e.g., ETRF2000). The procedure is described in chapter 4 and transformation parameters with rates are listed in Table 5 of Appendix 3 of memo v.8 (Boucher and Altamimi, 2011).

\begin{tabular}{|c|c|c|c|c|c|c|}
\hline Station & $X(\mathrm{~m})$ & $Y(\mathrm{~m})$ & $Z(\mathrm{~m})$ & $V_{X}(\mathrm{~m})$ & $V_{Y}(\mathrm{~m})$ & $V_{Z}(\mathrm{~m})$ \\
\hline & \multicolumn{6}{|c|}{ ITRF2008 $t_{c}=2005.00$} \\
\hline BOR1 & 3738358.453 & 1148173.709 & 5021815.772 & -0.0172 & 0.0156 & 0.0088 \\
\hline GOPE & 3979316.130 & 1050312.476 & 4857067.109 & -0.0158 & 0.0166 & 0.0103 \\
\hline WTZR & 4075580.553 & 931853.799 & 4801568.137 & -0.0158 & 0.0172 & 0.0104 \\
\hline UZHL & 3907587.452 & 1602428.685 & 4763783.749 & -0.0176 & 0.0164 & 0.0095 \\
\hline \multirow[t]{2}{*}{ WROC } & 3835751.306 & 1177249.962 & 4941605.252 & -0.0167 & 0.0160 & 0.0095 \\
\hline & \multicolumn{6}{|c|}{ ITRF2008 $t_{c}=2011.00$} \\
\hline BOR1 & 3738358.3498 & 1148173.8026 & 5021815.8248 & -0.0172 & 0.0156 & 0.0088 \\
\hline GOPE & 3979316.0352 & 1050312.5756 & 4857067.1708 & -0.0158 & 0.0166 & 0.0103 \\
\hline WTZR & 4075580.4582 & 931853.9022 & 4801568.1994 & -0.0158 & 0.0172 & 0.0104 \\
\hline UZHL & 3907587.3464 & 1602428.7834 & 4763783.8060 & -0.0176 & 0.0164 & 0.0095 \\
\hline \multirow[t]{2}{*}{ WROC } & 3835751.2058 & 1177250.0580 & 4941605.3090 & -0.0167 & 0.0160 & 0.0095 \\
\hline & \multicolumn{6}{|c|}{ ITRF2000 $t_{c}=2011.00$} \\
\hline BOR1 & 3738358.7707 & 1148173.4964 & 5021815.5722 & -0.0005 & -0.0005 & -0.0010 \\
\hline GOPE & 3979316.4398 & 1050312.2502 & 4857066.9044 & 0.0002 & -0.0004 & -0.0002 \\
\hline WTZR & 4075580.8501 & 931853.5689 & 4801567.9268 & -0.0004 & -0.0002 & -0.0003 \\
\hline UZHL & 3907587.7926 & 1602428.4661 & 4763783.5479 & 0.0003 & -0.0002 & -0.0006 \\
\hline \multirow[t]{2}{*}{ WROC } & 3835751.6252 & 1177249.7443 & 4941605.0514 & 0.0000 & -0.0005 & -0.0006 \\
\hline & \multicolumn{6}{|c|}{ ETRF2000 $t_{c}=2011.00$} \\
\hline BOR1 & 3738358.7707 & 1148173.4964 & 5021815.5722 & -0.0005 & -0.0005 & -0.0010 \\
\hline GOPE & 3979316.4398 & 1050312.2502 & 4857066.9044 & 0.0002 & -0.0004 & -0.0002 \\
\hline WTZR & 4075580.8501 & 931853.5689 & 4801567.9268 & -0.0004 & -0.0002 & -0.0003 \\
\hline UZHL & 3907587.7926 & 1602428.4661 & 4763783.5479 & 0.0003 & -0.0002 & -0.0006 \\
\hline WROC & 3835751.6252 & 1177249.7443 & 4941605.0514 & 0.0000 & -0.0005 & -0.0006 \\
\hline
\end{tabular}

Table 4

Transformation between ITRS and ETRS89 realizations of selected EPN stations 
As a final result, we get the coordinates of the current realization of ETRS89 system $\left(\mathrm{ETRF}_{X X}\right)$ at the average epoch $t_{c}$ of the GNSS campaign.

Actual realization of ITRS $\left(\right.$ ITRF $\left._{Y Y}\right)$ is ITRF2008 and ETRS89 $\left(\mathrm{ETRF}_{X X}\right)$ recommended by Technical Working Group (TWG) of EUREF is ETRF2000.

Many European countries are now updating official coordinates from ETRF89 to ETRF2000 by campaigns realized in reference to the EPN stations.

Table 4 shows an example of transformations between ITRF2008, ITRF2000 and ETRF2000 realizations according to the scheme shown in Fig. 20 and for the GNSS campaign at epoch $t_{c}=2011.00$ for selected EPN stations located close to Poland.

As shown in Table 4, the velocities for ITRF2008 and ITRF2000 are significant. The intra-plate velocities in ETRF2000 are not zero and not homogeneous. It is, therefore, necessary to conduct the selection of reference stations for diversifying EUREF in each country.

\section{Polish ETRS89 Realization}

In 1992, the EUREF was extended to the Polish territory. The initiative of this project was put forward by a team of scientists from the Committee of Geodesy of the Polish Academy of Sciences (BARAN and ZiELINSKI, 1992).

In 1992, the Head Office of Geodesy and Cartography in Poland requested the Department of Planetary Geodesy of the Space Research Centre, Polish Academy of Sciences to survey the EUropean REference Frame-POLand (EUREF-POL) network for the connection with the EUREF network (BARAN and Zielinski, 1993; JAworski et al., 2003). The EUREF-POL campaign was conducted from 4 to 8 July 1992. Eleven stations were surveyed (Fig. 21).

The EUREF-POL network diversification was carried out in 1994-95. The POLish REference Frame (POLREF) was established to provide the EUREF-89

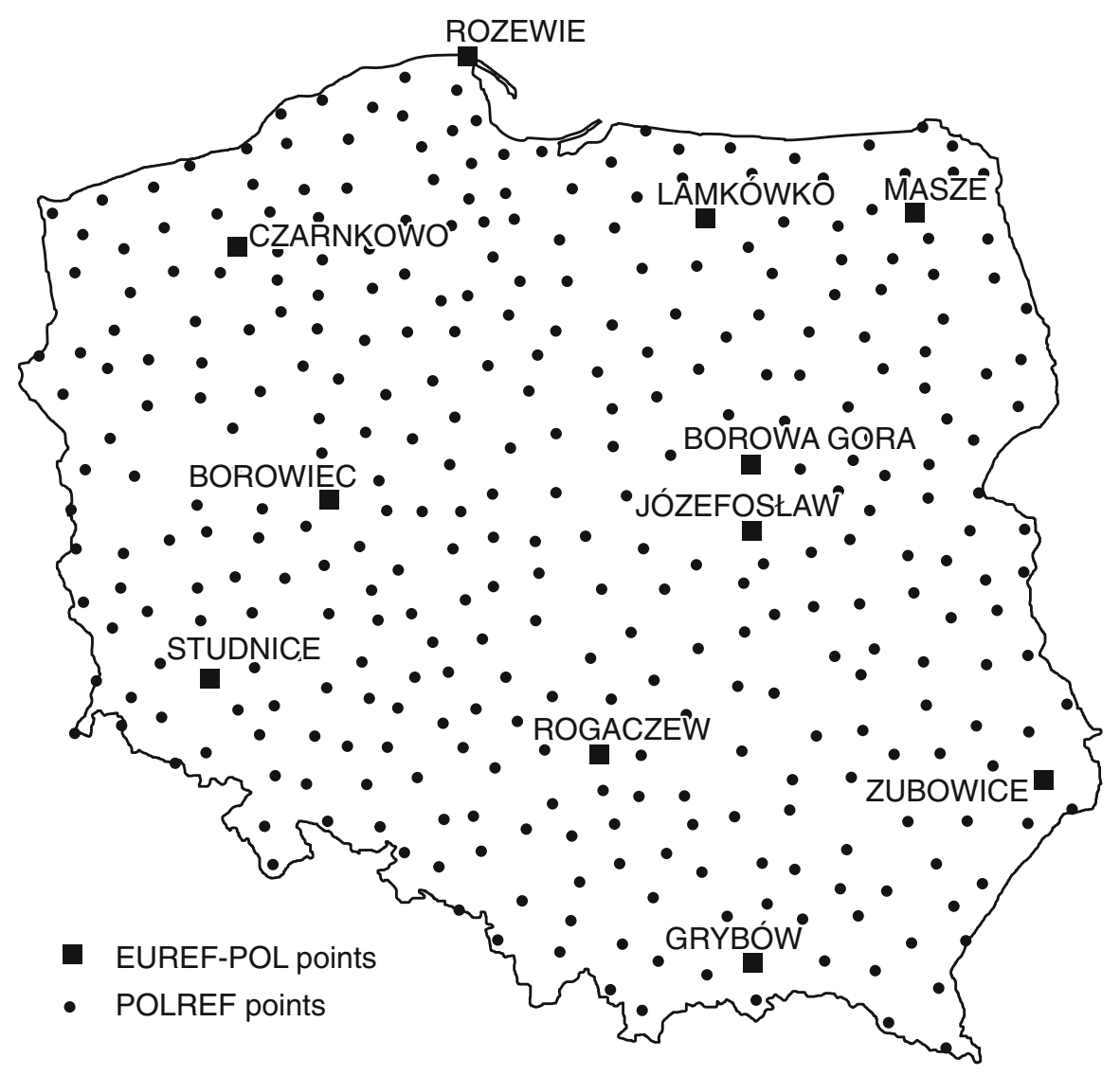

Figure 21

EUREF-POL and POLREF network points 


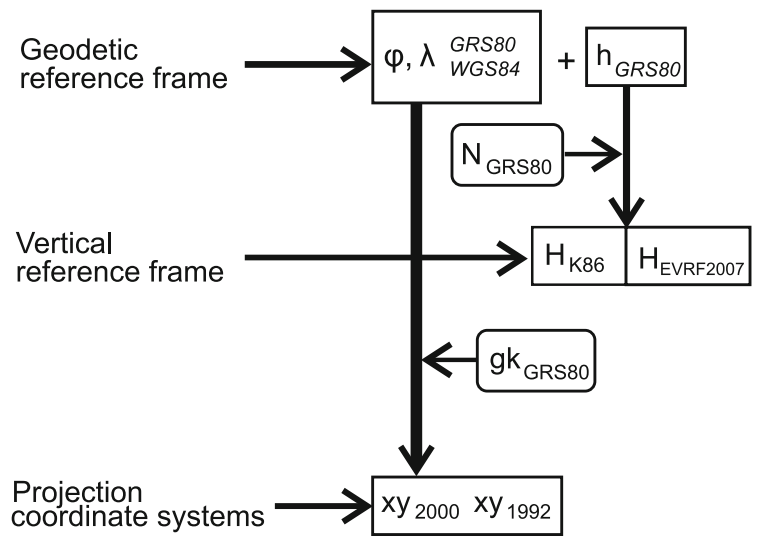

Figure 22

National spatial reference system (PSOP)

reference frame for geodetic, surveying and mapping applications (ZIELINSKI et al., 1998). The POLREF network consists of 348 points linked to 11 EUREFPOL stations. The average distance between points equals 25-35 km (Fig. 21).
A consequence of those actions was introduced by law in August 2000 for the National Spatial Reference System (PSOP). The Polish PSOP contains definitions and descriptions of the following elements (Fig. 22):

- Geodetic reference system and frame, called EUREF-89, is an extension of the European reference frame ETRF89 on Polish territory as a result of the diversification campaign EUREF-POL 92, the results of which were approved by the Subcommision for the European Reference System (EUREF), IAG in 1994.

- Vertical (height) reference system and frame, which is composed of gravitational potential values divided by the average values of the normal acceleration of gravity (the normal heights), referenced to the average level of the Baltic Sea in the Gulf of Finland, assigned to a reference point in Kronstadt near St. Petersburg (Russian Federation).

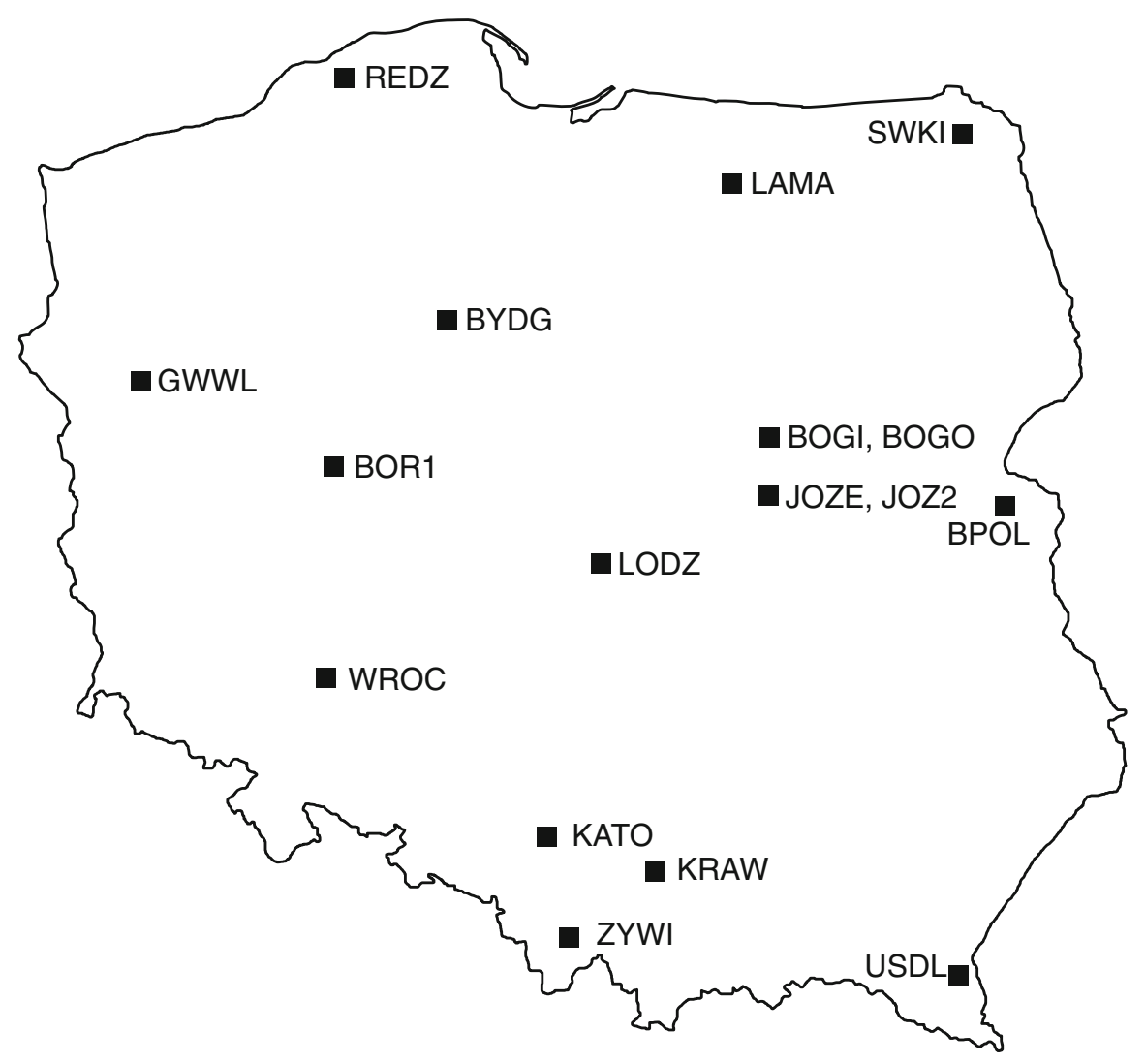

Figure 23

Polish EPN permanent stations 
- Projection coordinate systems (mapping sytems)flat rectangular coordinate systems 2000 and 1992, which are based on a mathematically unambiguous assignment of the Earth surface points to corresponding points on the plane according to the theory of cartographic Gauss-Krüger projection.

The connection between Polish PSOP elements are shown in Fig. 22.

The element that binds all the components of the Polish PSOP system is the ellipsoid GRS80 (Fig. 22).
The polar coordinates $(B . L$ or $\varphi, \lambda)$ in the geodetic reference system above refers to the GRS80 (WGS84) ellipsoid. The quasi-geoid heights $\left(H_{K 86}\right.$ or $H_{\text {ETRV2007) }}$ are also referenced to the GRS80 (WGS84) ellipsoid. Also, for mapping systems $\left(x y_{2000}\right.$ and $\left.x y_{1992}\right)$ ellipsoid GRS80 projections are used. This greatly facilitates the practical usage of the system and unifies the calculations, such as Geographic Information System applications.

In the early 1990's Polish research centers launched GPS permanent stations (Borowiec: BOR1,

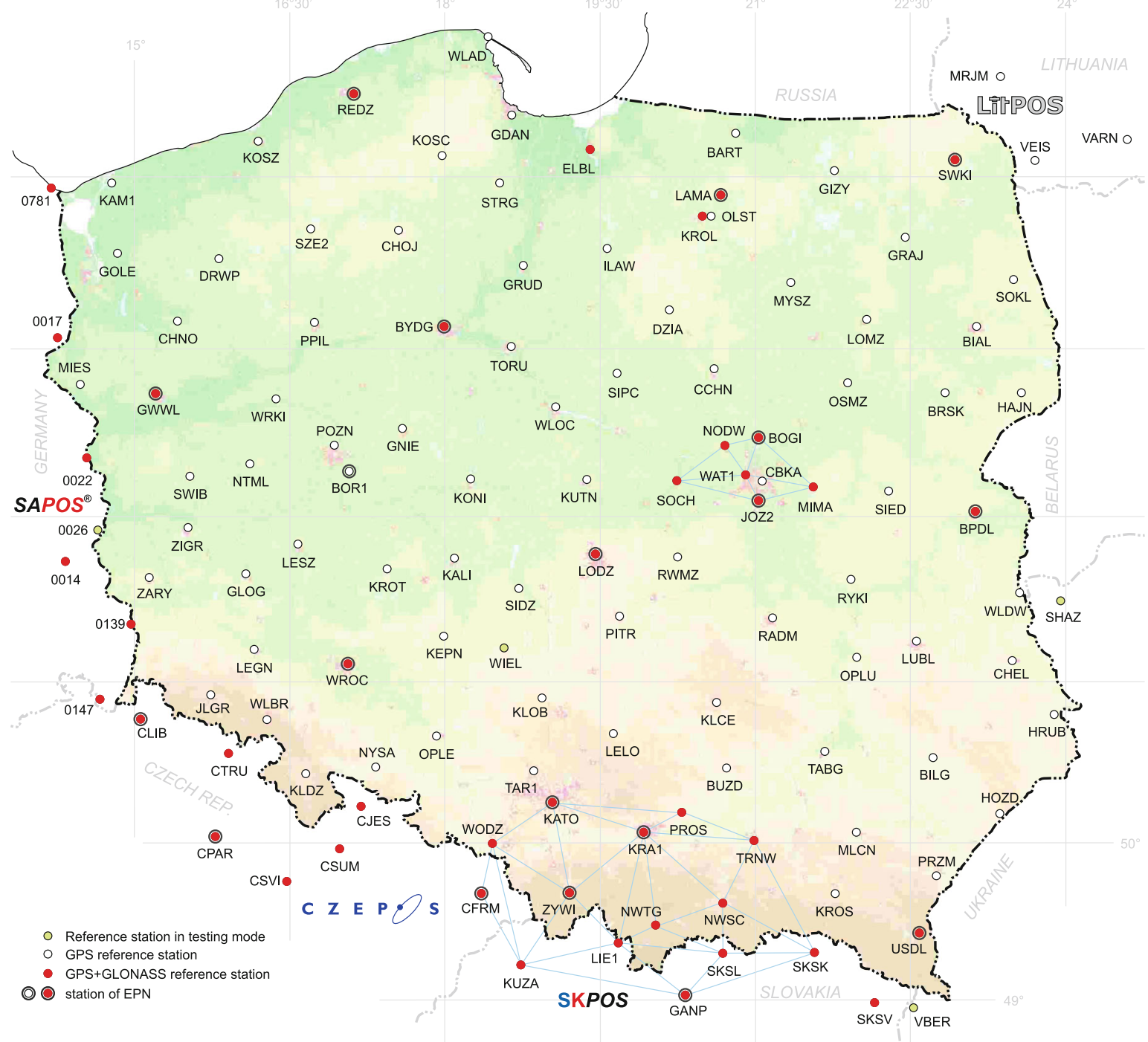

Figure 24

Distribution of ASG-EUPOS reference stations (With kind permission from Bujakowski-Surveyor General of Poland. source http:// www.asgeupos.p1/webpg/graph/dwnld/map_en_dwnld.jpg, (c) Head Office of Geodesy and Cartography Poland 2013) 
Borowa Gora: BOGO, Jozefoslaw: JOZE, Lamkowko: LAMA, Wroclaw: WROC). Those stations were included in the EPN network from the very beginning of its operation. Gradually, additional stations in Poland (Krakow: KRAW, Borowa Gora: BOGI, Jozefoslaw: JOZ2) were included. In 2003, the Head Office of Geodesy and Cartography (GUGiK) included next in the ASG-PL project two stations to the EPN network (Katowice: KATO and Zywiec: ZYWI). In 2008, the EPN network in Poland was extended within the ASG-EUPOS project carried out by seven consecutive GUGiK Polish stations (Biala Podlaska: BPDL, Bydgoszcz: BYDG, Gorzow Wielkopolski: GWWL, Lodz: LODZ, Redzikowo: REDZ, Suwalki: SWKI, Ustrzyki Dolne: USDL). Currently, 17 Polish stations operate in the EPN network, their location is shown in Fig. 23.
Polish part of the EPN network (Fig. 23) is currently a representative collection of fundamental points that correspond to the EUREF-POL network (Fig. 21). The new national permanent GNSS network ASG-EUPOS (densification of EPN) has been established by the Head Office of Geodesy and Cartography (GUGiK) in Poland since 2008 (http:// www.asgeupos.pl). The ASG-EUPOS network consists (including foreign stations) of about 120 GNSS reference stations located evenly on the country area and have a greater density than the EPN network (Fig. 24).

The ASG-EUPOS network will define the geodetic reference system in Poland. A close connection of the ASG-EUPOS stations and 15 of 17 stations of the EPN that are located in the territory of Poland will control the realization of the ETRS89 system at the Polish territory.

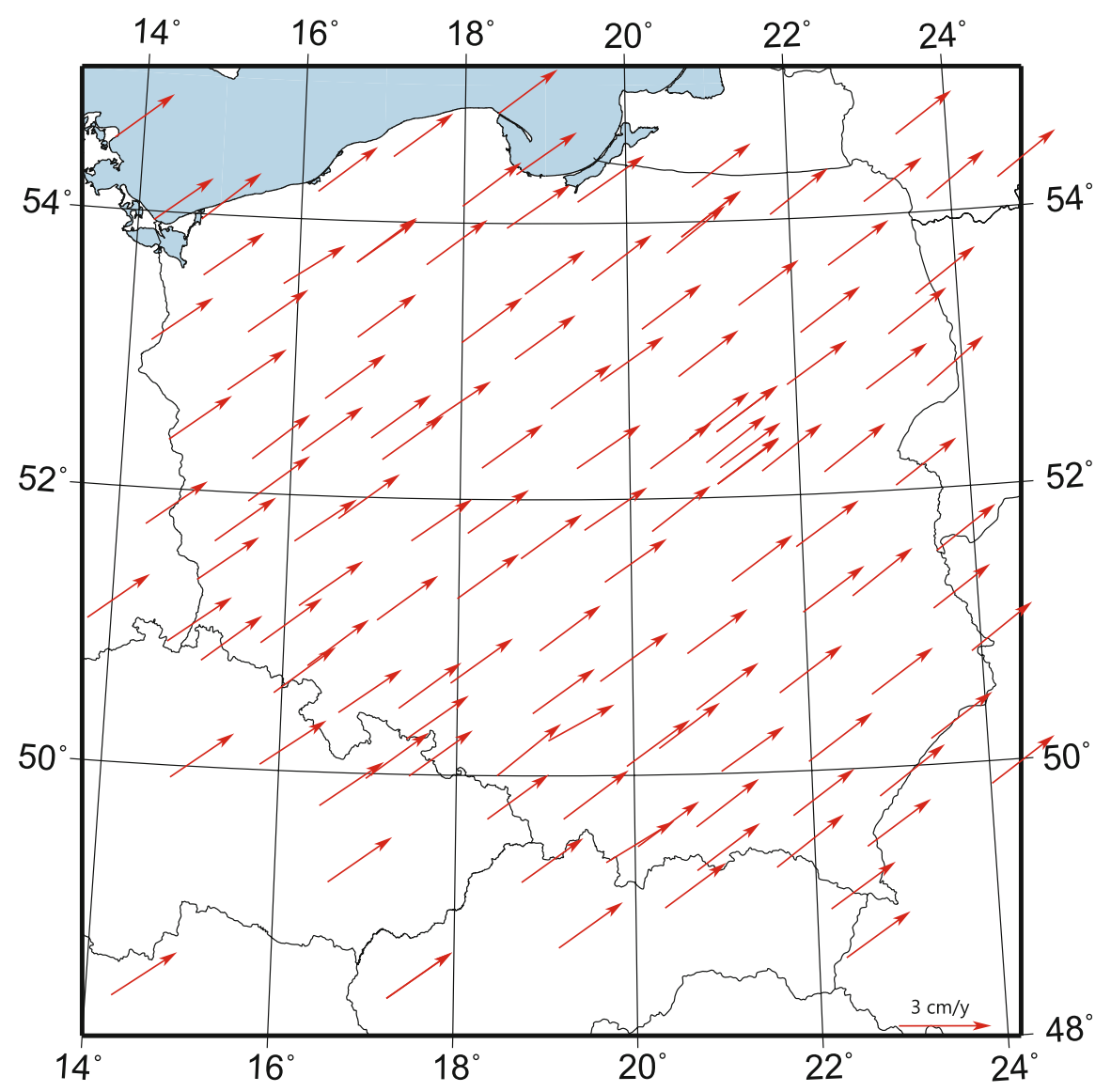

Figure 25

ITRF2008 of ASG-EUPOS stations horizontal velocities determined by CAG MUT (With kind permission from Bogusz) 
Since 2008, the permanent analysis of time series coordinates of ASG-EUPOS network stations in actual ITRS realization (ITRF2008) are provided by the Centre of Applied Geomatics of the Military University of Technology in Warsaw (CAG MUT: http://www.cgs.wat.edu.pl) (Bogusz et al., 2012a, b). Figure 25 shows the ITRF2008 horizontal velocities of ASG-EUPOS stations (Bogusz et al., 2012a, b).

The velocities shown in Fig. 25 are very similar to ITRS horizontal velocities computed by IGS and EPN analysis centers. The ITRS (currently ITRF2008) coordinates are transformed to ETRS89 (currently ETRF2000) using formulas and parameters published in memo v.8 (Boucher and Altamimi, 2011), and finally weekly solutions are published by CAG MUT. Figure 26 show the ETRF2000 horizontal residual (intraplate) velocities of ASG-EUPOS stations published by CAG MUT.
Figures 27 and 28 show the ITRF2008 and ETRF2000 vertical velocities (KonTnY and Bogusz, 2012).

Nowadays the reliable determination of horizontal and vertical velocities of permanent stations is an indispensable element in the correct realization of the reference system. The horizontal and vertical velocities in ETRS89 (e.g., ETRF2000) give us the possibility of transforming coordinates between ETRS89 realizations and control stability of catalog coordinates of the national base network.

In the present national legislation, the Polish part of the EPN network (Fig. 23) is currently a representative collection of fundamental points that correspond to the EUREF-POL network (Fig. 21). Similarly, the ASG-EUPOS network (Fig. 24) is an alternative to the POLREF network (Fig. 21). ETRS89 was originally extended to the Polish

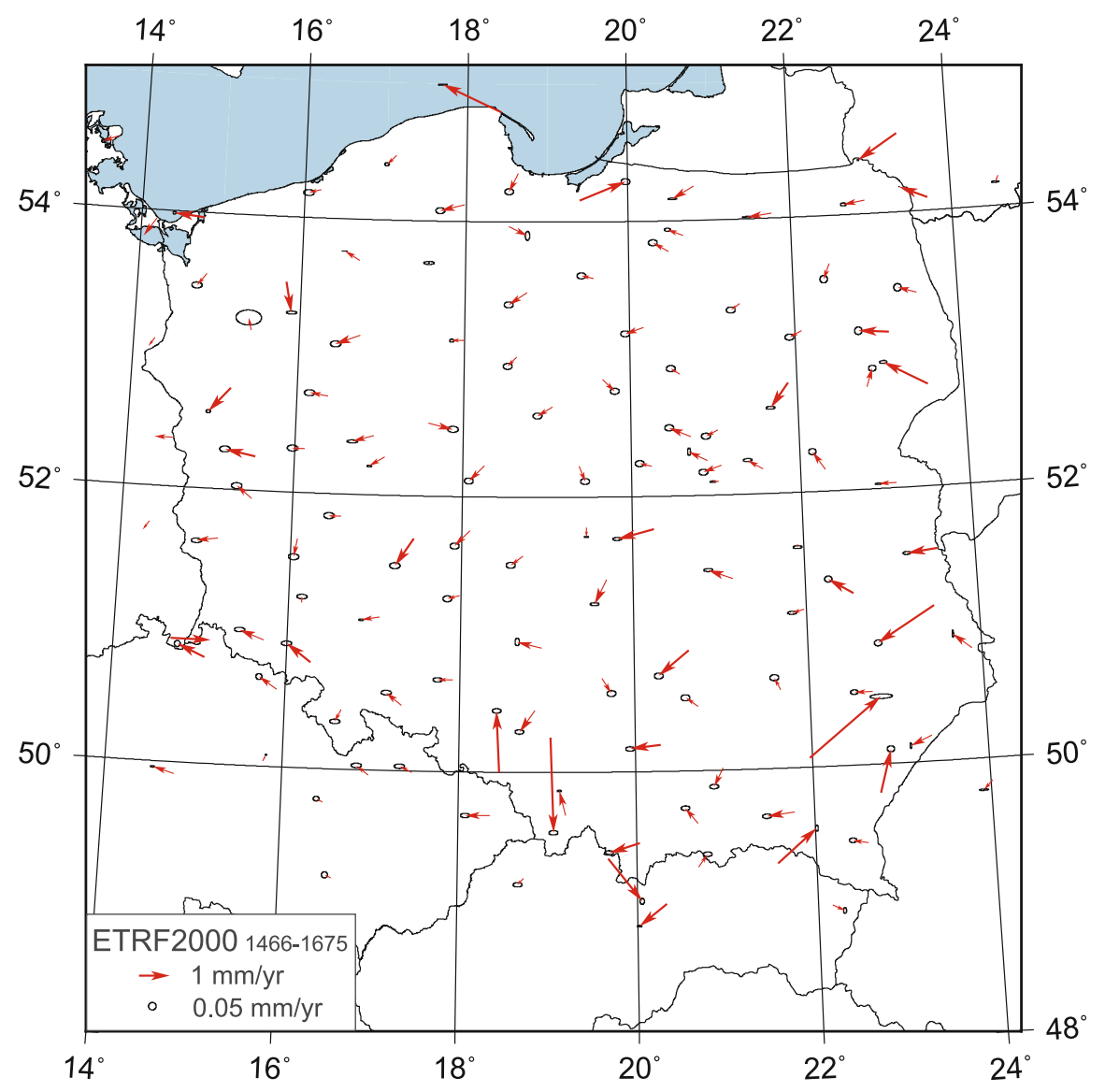

Figure 26

ETRF2000 of ASG-EUPOS stations horizontal velocities determined by CAG MUT (With kind permission from: Bogusz) 


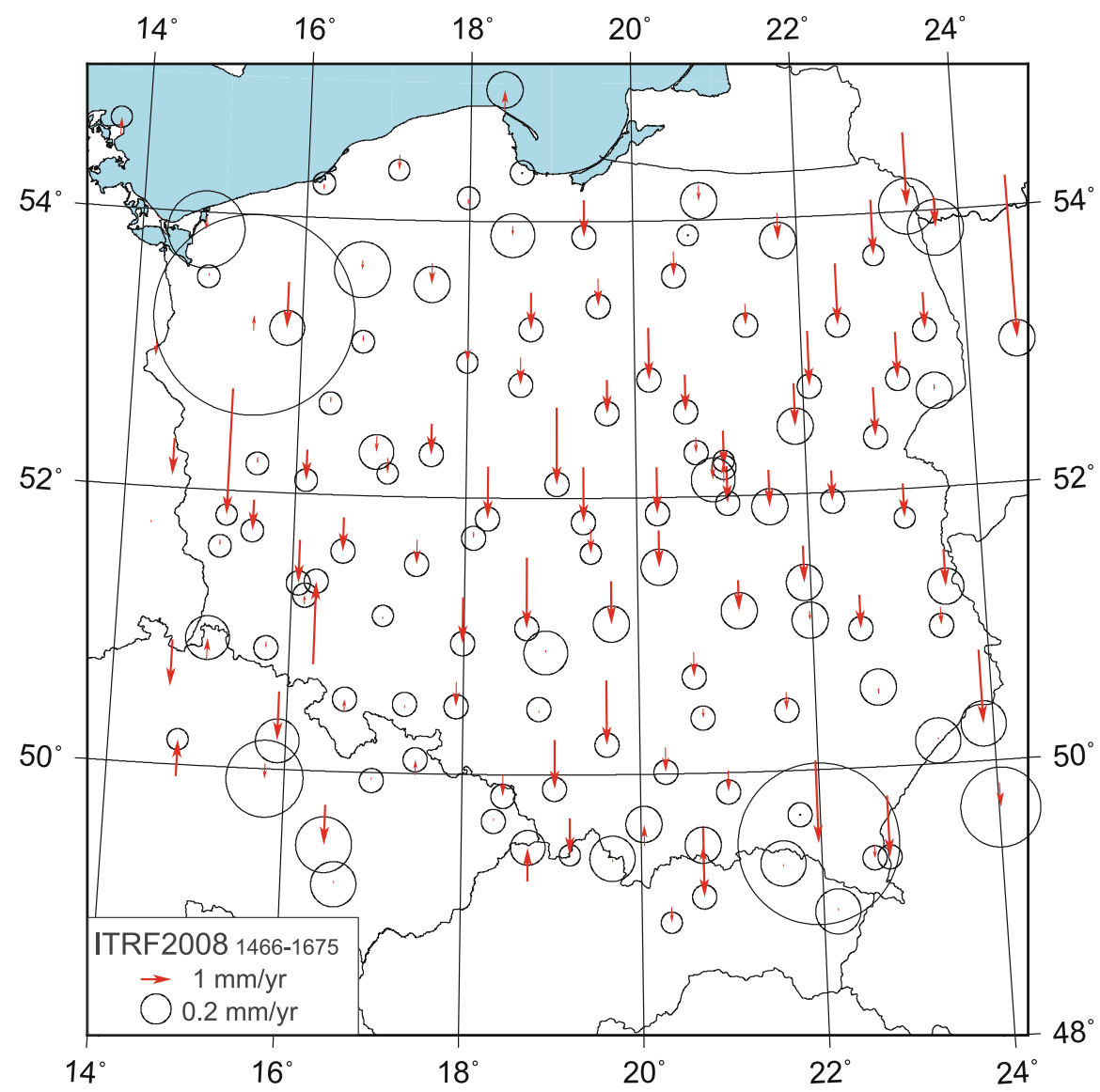

Figure 27

ITRF2008 of ASG-EUPOS stations vertical velocities determined by CAG MUT (With kind permission from Bogusz)

territory by the EUREF-POL and POLREF networks measured in repetitive epochal campaigns.

Currently the ASG-EUPOS system offer precise positioning services in postprocessing and real-time mode, and provides a homogeneous reference frame for GNSS users in the territory of Poland. The system include three independent levels (Fig. 29) for the control of the stability of the ETRS89 realization in Poland (Bosy et al., 2008).

The first level of control is being realized by the EPN Analysis Centers that each week calculate the coordinates of regularly distributed GNSS stations on Polish territory. The ASG EUPOS Processing Centre calculates the network on a daily basis according to the EPN standards, using Bernese GPS Software (v5.0). This procedure is used for a second level control of the stability of the ETRS89 for the Polish territory. Third control level is delivered by the
Trimble GPSNet software and the reference frame is transmitted to the end users. The ASG-EUPOS system is actually a stable and uniform ETRS89 reference system realization in Poland.

\section{Summary}

The usage of satellite techniques: VLBI, SLR, DORIS and especially GNSS in geodesy, allows unification of the reference system at global, regional and national levels. The ITRS provides a stable basis for uniform measurements and determining the position of objects on or near the Earth's surface.

The European Terrestrial Reference System ETRS89 is the EU-recommended frame of reference for geodata in Europe. The EUREF is the geodetic infrastructure for multinational projects requiring 


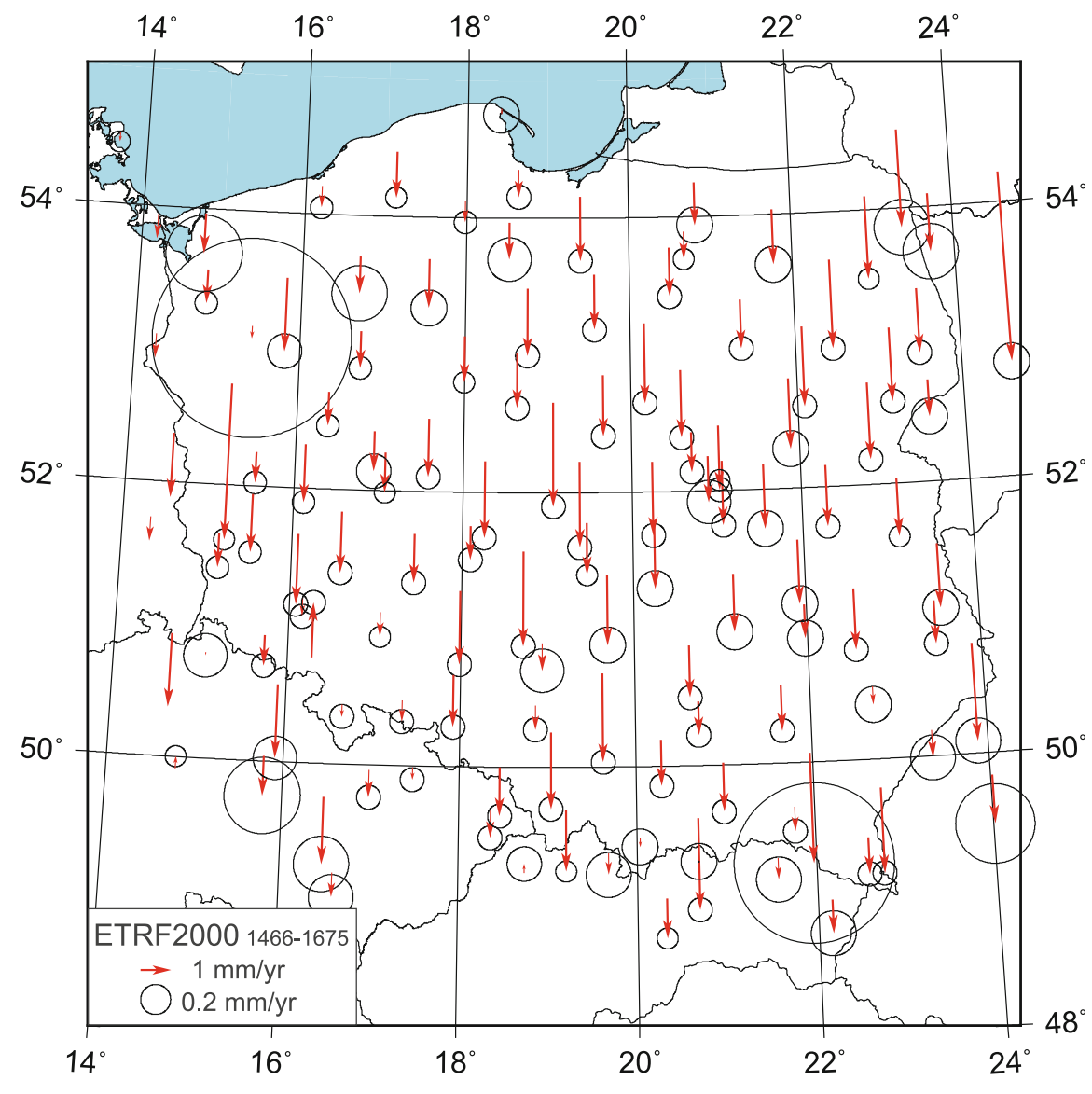

Figure 28

ETRF2000 of ASG-EUPOS stations vertical velocities determined by CAG MUT (With kind permission from Bogusz)

First control level

EUREF Permanent GNSS Network Polish reference stations

Second control level

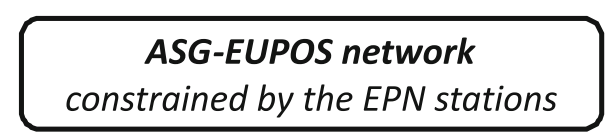

Third control level

ASG-EUPOS services

reference frame is transmitted to end users

Figure 29

ETRS89 realization and control via the ASG-EUPOS system 
precise geo-referencing (e.g., three-dimensional and time dependent positioning, geodynamics, precise navigation, geo-information).

The European Reference Frame (EUREF) is realized in close cooperation with the IAG components (Services, Commissions, and Inter-commision projects) and EuroGeographics, the consortium of the National Mapping Agencies (NMA) in Europe.

The National Spatial Reference System (PSOP) is a consistent and unified coordinate system that defines latitude, longitude, height and horizontal coordinates in Poland.

\section{Acknowledgments}

The author thanks all those who have agreed with him to use their figures published in journals, books and on the Internet.

Open Access This article is distributed under the terms of the Creative Commons Attribution License which permits any use, distribution, and reproduction in any medium, provided the original author(s) and the source are credited.

\section{REFERENCES}

Altamimi Z., Angermann D., Argus D., Blewitt G., Boucher C., Chao B., Drewes H., Eanes R., Feissel M., Ferland R., Herring T., Holt B., Johannson J., Larson K., Ma C., Manning J., Meertens, C., Nothnagel, A., Pavlis, E., Petit, G., Ray, J., Ries, J., Scherneck, H.-G., Sillard, P., Watkins, M., (2001) The terrestrial reference frame and the dynamic Earth. Eos Trans. AGU 82(25):273-279, doi:10.1029/EO082i025p00273-01.

Altamimi Z., Boucher C., Willis P. (2005) Terrestrial reference frame requirements within GGOS perspective. Journal of Geodynamics 40:(45) 363-374. http://www.sciencedirect.com/science/ article/pii/S0264370705000682

Altamimi Z., CollilieuX X., Métivier L. (2011) ITRF2008: an improved solution of the international terrestrial reference frame. Journal of Geodesy 85(8):457-473. doi:10.1007/s00190011-0444-4

Argus, D.F., Gordon, R.G. (1991) No-net rotation model of current plate velocities incorporating plate motion model NUVEL-1. Geophysical Research Letters 18(11):2039-2042

Baran W., Zielinski J.B. (1992) Design and Preparation of the EUREF-92 GPS Campaign in Poland, Report on the Symposium of the IAG Subcommission for the European Reference Frame (EUREF), held in Berne, 4-6 March 1992. In: Verffentlichungen der Bayerischen Kommission fnr die Internationale Erdmessung der Bayerischen Akademie der Wissenschaften, AstronomischGeodStische Arbeiten. No. 52 in EUREF Publication. Verlag der Bayerischen Akademie der Wissenschaften, pp. 233-235.
Baran W., Zielinski J.B. (1993) Status Report on Participation of Poland in Creation of European Reference Frame EUREF, Report on the Symposium of the IAG Subcommission for the European Reference Frame (EUREF), held in Budapest, 17-19 May 1993. In: Verffentlichungen der Bayerischen Kommission für die Internationale Erdmessung der Bayerischen Akademie der Wissenschaften, Astronomisch- GeodStische Arbeiten. No. 53 in EUREF Publication. Verlag der Bayerischen Akademie der Wissenschaften, pp. 160-163.

Beutler G., Moore A., Mueller I. (2009) The international global navigation satellite systems service (IGS): development and achievements. Journal of Geodesy 83:297-307. doi:10.1007/ s00190-008-0268-z

Böckmann, S., Artz, T., Nothnagel, A. (2010) VLBI terrestrial reference frame contributions to ITRF2008. Journal of Geodesy 84:201-219. doi:10.1007/s00190-009-0357-7

Bogusz J., Figurski M., Kontny B., Grzempowski P. (2012a) Unmodeled effects in the horizontal velocity fields: ASG-EUPOS case study. Artificial Satellites 47(2):67-79.

Bogusz J., Figurski M., Kontny B., Grzempowski P. (2012b) Uorizontal velocity field derived from EPN and ASG-EUPOS satellite data on the example of south-western part of Poland. Acta Geodynamica et Geomaterialia 9(3):349-357

Bosy J., Kontny B., Borkowski A. (2009) IGS/EPN Reference Frame Realization in Local GPS Networks. In: Drewes, H. (Ed.), Geodetic Reference Frames. Vol. 134 of International Association of Geodesy Symposia. Springer Berlin Heidelberg, pp. 197-203.

Bosy J., Oruba A., Graszka W., Leonczyk M., Ryczywolski M. (2008) ASG-EUPOS densification of EUREF Permanent Network on the territory of Poland. Reports on Geodesy 2(85):105-112

Boucher C., Altamimi Z. (1996) International Terrestrial Reference Frame. GPS World 7(9):71-74.

Boucher C., Altamimi Z. (2011) Memo: Specifications for reference frame fixing in the analysis of a EUREF GPS campaign. http://etrs89.ensg.ign.fr/memo-V8.pdf

Bruyninx C., Altamimi Z., Caporali A., Kenyeres A., Lidberg M., Stangl G., Torres J. (2012a) Guidelines for EUREF Densifications, IAG sub-commission for the European Reference Frame EUREF. ftp://epncb.oma.be/pub/general/Guidelines_for_EUREF_ Densifications.pdf

Bruyninx C., Habrich H., Shne W., Kenyeres A., Stangl G., VlKSEN C. (2012b) Enhancement of the EUREF Permanent Network Services and Products. In: Kenyon, S., Pacino, M. C., Marti, U. (Eds.), Geodesy for Planet Earth. Vol. 136 of International Association of Geodesy Symposia. Springer Berlin Heidelberg, pp. 27-34. doi:10.1007/978-3-642-20338-1_4

DeMets C., Gordon R.G., Argus D.F., Stein S. (1994) Effect of recent revisions to the geomagnetic reversal time scale on estimates of current plate motions. Geophysical Research Letters 21(20):2191-2194

Dow J.M., NeIlan R., Rizos C. (2009) The International GNSS Service in a changing landscape of Global Navigation Satellite Systems. Journal of Geodesy 83:191-198. doi:10.1007/s00190008-0300-3

FERLAND R. (2010) Description of IGS submission to ITRF2008, available at: http://itrf.ensg.ign.fr/ITRF_solutions/2008/doc/ IGSsubmission4ITRF2008.txt.

Ferland R., Piraszewski M. (2009) The IGS-combined station coordinates, earth rotation parameters and apparent geocenter. Journal of Geodesy 83:385-392. doi:10.1007/s00190-008-0295-9 
Jaworski L., Swiatek A., Zdunek R., Zielinski J.B. (2003) Results of the EUREF-POL-2001 GPS Campaign. In: Symposium of the IAG Subcommission for Eu-rope (EUREF) held in Ponta Delgada, 5-8 June 2002. No.29 in EUREF Publication. Verlag des Bundesamtes fur Kartographie und Geodasie, Frankfurt am Main, pp. 185-197.

KENYERES A. (2009) Maintenance of the EPN ETRS89 coordinates/ Maintenance of the ETRS89 using EPN, eUREF TWG 2009 spring meeting, Budapest 26-27 February 2009.

KenYeRES A. (2012) The implementation of IGS08 in the EPN ETRS89 maintenance products. Tech. rep., FÖMI Satellite Geodetic Observatory, Hungary, EPN Reference Frame Coordinator, Version 19 October 2012.

Kontny B., Bogusz J. (2012) Models of vertical movements of the Earth crust surface in the area of Poland derived from leveling and GNSS data. Acta Geodynamica et Geomaterialia 9(3):331-337

Noll C.E. (2010) The crustal dynamics data information system: A resource to support scientific analysis using space geodesy. Advances in Space Research 45(12):1421-1440. http:// www.sciencedirect.com/science/article/pii/S0273117710000530

Pavlis E., Luceri C., Sciarretta C., Kelm R. (2010) The ILRS contribution to ITRF2008, available at: http://itrf.ensg.ign.fr/ ITRF_solutions/2008/doc/ILRSSubmission4ITRF2008.pdf.

Pearlman M., Degnan J., Bosworth J. (2002) The International Laser Ranging Service. Advances in Space Research 30(2):135-143 http://www.sciencedirect.com/science/article/pii/ S0273117702002776

Pearlman M., Noll C., Dunn P., Horvath J., Husson V., Stevens P., Torrence M., Vo H., Wetzel S. (2005) The International Laser Ranging Service and its support for IGGOS. Journal of Geodynamics 40(45):470-478 http://www.sciencedirect.com/ science/article/pii/S0264370705000773

Petit G., Luzum B. (Eds.) (2010) IERS Conventions (2010). IERS Technical Note 36. Verlag des Bundesamts fnr Kartographie und GeodSsie, Frankfurt am Main.

Plag H.-P., Gross R., Rothacher M., (2009) Global Geodetic Observing System for Geohazards and Global Change. Geosciences 9:96-103

Plag H.-P., Pearlman M. (Eds.), (2009) Global Geodetic Observing System. Meeting the Requirements of a Global Society on a Changing Planet in 2020. Springer Verlag.

Rothacher M., Beutler G., Behrend D., Donnellan A., Hinderer J., Ma C., Noll C., Oberst J., Pearlman M., Plag H.-P., Richter
B., Schne T., Tavernier G., Woodworth P. (2009) The future Global Geodetic Observing System. In: Plag, H.-P., Pearlman, M. (Eds.), Global Geodetic Observing System. Springer Berlin Heidelberg, pp. 237-272. doi:10.1007/978-3-642-02687-4_9

SChlnter W., Behrend D. (2007) The International VLBI Service for Geodesy and Astrometry (IVS): current capabilities and future prospects. Journal of Geodesy 81:379-387. doi:10.1007/ s00190-006-0131-z

SCHLÜTER W., BEHREND D. (2007) The International VLBI Service for Geodesy and Astrometry (IVS): current capabilities and future prospects. Journal of Geodesy 81(6-8):379-387

Schun H., Behrend D. (2012) VLBI: A fascinating technique for geodesy and astrometry. Journal of Geodynamics 61(0):68 - 80 http://www.sciencedirect.com/science/article/pii/S02643707120 01159

SEeber G. (2003) Satellite Geodesy, 2nd Edition. Walter de Gruyter GmbH \& Co. Berlin New York.

Seeger H., Augath W., Bordley R., Boucher C., Engen B., Gurtner W., Schlnter W., Sigl R. (1992) Status-report on the EUREF-GPS-Campaign 1989 to the IAG EUREF-Subcommmission. In: Verffentlichungen der BEK, AstronomischGeodStische Arbeiten. No. 52 in Report on the Symposium of the IAG Subcommission for the European Reference Frame (EUREF). Verlag der Bayerischen Akademie der Wissenschaften, pp. 26-34.

Seidelmann P.K. (1982) 1980 IAU Nutation: The Final Report of the IAU Working Group on Nutation. Celest. Mech. 27:79-106.

Valette J.-J., Lemoine F.G., Ferrage P., Yaya P., Altamimi Z., WILlis P., Soudarin L. (2010) IDS contribution to ITRF2008. Advances in Space Research 46(12):1614-1632. http:// www.sciencedirect.com/science/article/pii/S0273117710003741

Willis P., Fagard H., Ferrage P., Lemoine F.G., Noll C.E., Noomen R., Otten M., Ries J.C., Rothacher M., Soudarin L., TAVernier G., Valette J.-J. (2010) The International DORIS Service (IDS): Toward maturity. Advances in Space Research 45(12):1408-1420 http://www.sciencedirect.com/science/article/ pii/S0273117709007212

Zielinski B., Lyszkowicz A., Jaworski L., Swiatek A., Zdunek R., Gelo, S. (1998) Polref-96 - the New Geodetic Reference Frame for Poland. In: Brunner, K.F. (Ed.), Advances in Positioning and Reference Frames. Vol. 118 of International Association of Geodesy Symposia. IAG Scientific Assembly, Rio de Janeiro, Brazil, September, 3-9, 1997, Springer-Verlag Berlin Heidelberg New York, pp. 161-166. 